Um método híbrido para o problema de dimensionamento de lotes

Luiz Henrique Cherri 
SERVIÇO DE PÓS-GRADUAÇÃO DO ICMC-USP

Data de Depósito:

Assinatura:

\title{
Um método híbrido para o problema de dimensionamento de lotes
}

\author{
Luiz Henrique Cherri
}

Orientadora: Profa. Dra. Franklina Maria Bragion de Toledo

\begin{abstract}
Dissertação apresentada ao Instituto de Ciências Matemáticas e de Computação - ICMC-USP, como parte dos requisitos para obtenção do título de Mestre em Ciências - Ciências de Computação e Matemática Computacional. VERSÃO REVISADA.
\end{abstract}


Ficha catalográfica elaborada pela Biblioteca Prof. Achille Bassi e Seção Técnica de Informática, ICMC/USP, com os dados fornecidos pelo(a) autor(a)

\begin{tabular}{|c|c|}
\hline $\mathrm{C} 521 \mathrm{~m}$ & $\begin{array}{l}\text { Cherri, Luiz Henrique } \\
\text { Um método híbrido para o problema de } \\
\text { dimensionamento de lotes / Luiz Henrique Cherri; } \\
\text { orientadora Franklina Maria Bragion Toledo. -- São } \\
\text { Carlos, } 2013 \text {. } \\
\quad 65 \mathrm{p} \text {. }\end{array}$ \\
\hline & $\begin{array}{l}\text { Dissertação (Mestrado - Programa de Pós-Graduação en } \\
\text { Ciências de Computação e Matemática Computacional) -- } \\
\text { Instituto de Ciências Matemáticas e de Computação, } \\
\text { Universidade de São Paulo, 2013. }\end{array}$ \\
\hline & $\begin{array}{l}\text { 1. Dimensionamento de lotes. 2. Busca tabu. } 3 \text {. } \\
\text { Branch-and-cut. I. Toledo, Franklina Maria Bragion, } \\
\text { orient. II. Título. }\end{array}$ \\
\hline
\end{tabular}





\section{Agradecimentos}

- A Deus, por ter sempre me guiado e iluminado.

- À Professora Franklina pela orientação, dedicação e amizade.

- Aos meus pais Luiz e Maria, pelo amor, compreensão, apoio e dedicação incondicional que sempre tiveram por mim.

- Aos meus irmãos César e Adriana e a toda minha família pelo carinho e incentivo.

- Aos meus amigos: Aline, Andresa, Arthur, Daniel, Gabriela, Jeinny, Lucas, Marcio, Marcos, Mayron, Paula, Victor e a todos os colegas e professores do Laboratório de Otimização pela ajuda, paciência e pelas boas conversas e risadas.

- Aos professores e funcionários do ICMC-USP que, direta ou indiretamente, contribuíram com este trabalho.

- À FAPESP pelo apoio financeiro.

- Enfim, agradeço a todos que me ajudaram a finalizar mais um capítulo de minha vida. 



\section{Resumo}

Neste trabalho, abordamos métodos de resolução para o problema de dimensionamento de lotes que contempla o planejamento da produção de vários produtos em múltiplas máquinas. A fabricação dos produtos consome tempo de produção e preparação de uma capacidade de produção limitada. A demanda pelos produtos é conhecida e pode ser atendida com atraso durante um horizonte de planejamento finito. O objetivo é minimizar a soma dos custos de produção, preparação para a produção, estoque dos produtos e atraso na entrega destes. Em uma primeira etapa, desenvolvemos uma busca tabu determinística baseada em outra, aleatória, que foi apresentada na literatura. Com isso, realizamos uma análise sobre a influência de fatores aleatórios sobre heurísticas do tipo busca tabu quando aplicadas ao problema estudado. Posteriormente, desenvolvemos um método híbrido baseado em busca tabu, branch-and-cut e programação linear para a resolução do problema. Nos testes computacionais realizados, o método proposto mostrou-se competitivo quando comparado a outras heurísticas apresentadas na literatura. 



\begin{abstract}
This paper proposes two methods to solve the capacitated lot-sizing problem with multiple products and parallel machines. The manufacturing of products consumes machines capacity (production time and setup time), which is scarce. The demand for the products is known and can be met with backlogging. The objective is to minimize the sum of production, setup, holding and backlog costs. In a first step, we developed a deterministic tabu search heuristic based on a random version from the literature and then conducted an analysis of the influence of random factors on tabu search heuristics when applied to solve the studied problem. Subsequently, we designed a hybrid method based on tabu search, branch-andcut and linear programming. Computational experiments show that this hybrid method is competitive with other heuristics presented in the literature.
\end{abstract}





\section{Sumário}

$\begin{array}{lll}1 & \text { Introdução } & 13\end{array}$

\begin{tabular}{|lll}
2 & O problema de dimensionamento de lotes & 15
\end{tabular}

2.1 Introdução . . . . . . . . . . . . . . . . . . . . . . . . . . . . . . . . . . . . . . . . . . .

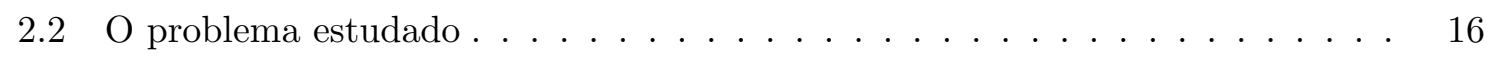

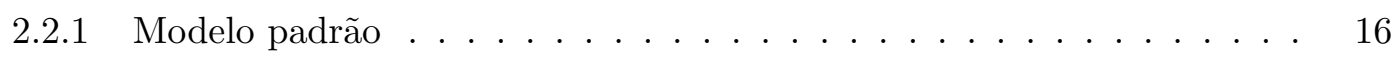

2.2 .2 Reformulação baseada em $\mid$ Krarup e Bilde[(1977)] . . . . . . . . . . . . 17

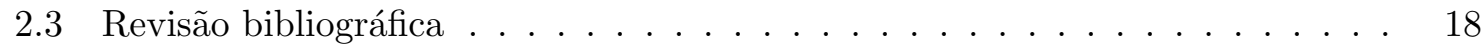

$2.3 .1 \quad$ Problemas com uma única máquina e um único produto . . . . . . . . 19

2.3.2 Múltiplos produtos com restrições de capacidade e custos de preparação

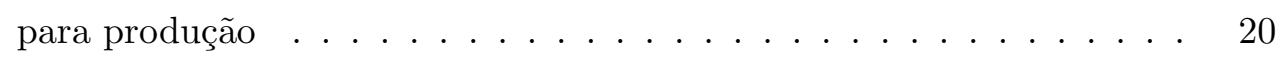

2.3 .3 Múltiplos produtos com restrições de capacidade, custo e tempo para

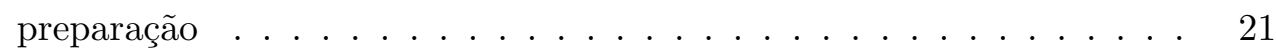

$2.3 .4 \quad$ Problemas com múltiplas máquinas e múltiplos produtos . . . . . . . 22

3 Análise do impacto da aleatoriedade sobre heurísticas busca tabu hídridas 25

3.1 Conceitos básicos . . . . . . . . . . . . . . . . . . . 26

3.1 .1 Busca tabu . . . . . . . . . . . . . . . . . . . . . . . . . . . . . . . . . . . 26

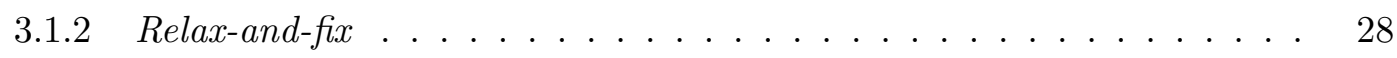

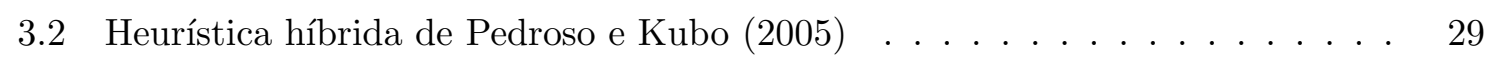

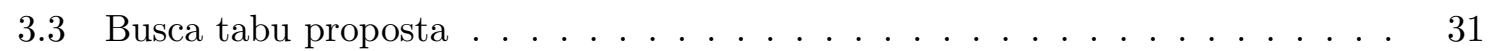

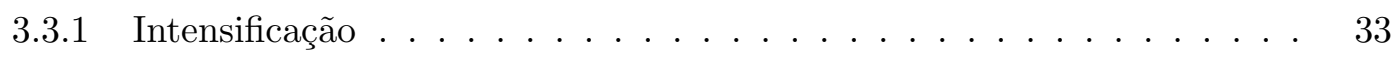

3.3 .2 Diversificação . . . . . . . . . . . . . . . . . . . . . 33

$3.3 .3 \quad$ Busca tabu com memória de longo prazo . . . . . . . . . . . . . . . . 34

3.4 Resultados . . . . . . . . . . . . . . . . . . . . . . 34

$3.4 .1 \quad$ Primeira etapa de testes (1 máquina $\ldots \ldots \ldots \ldots$. . . . . . . . 35

3.4 .2 Segunda etapa de testes (máquinas paralelas) . . . . . . . . . . . . . . . . . . 38

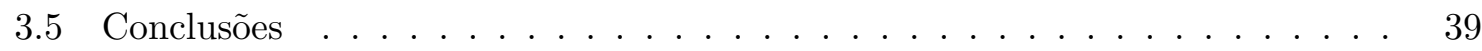

4 Método Híbrido $\quad 41$

4.1 Proposta de Woodcock e Wilson $[(2010)] \ldots \ldots$. . . . . . . . . . . . . 41

$4.2 \quad$ Método híbrido proposto . . . . . . . . . . . . . . . . . . . . 43

4.2 .1 Inicialização . . . . . . . . . . . . . . . . . . . . . . . 44 
$4.2 .2 \quad$ Busca tabu com memória de curto prazo . . . . . . . . . . . . . . 45

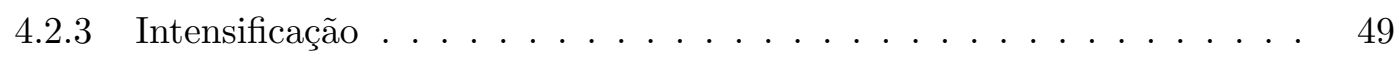

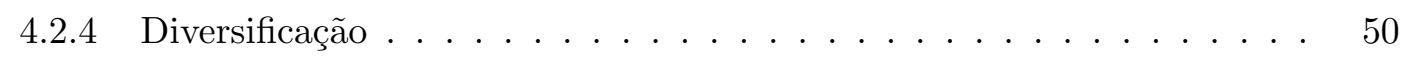

4.2 .5 Busca tabu com vizinhança abrangente (BTVA) . . . . . . . . . . . . . . 50

4.3 Testes computacionais $\ldots \ldots \ldots \ldots \ldots \ldots \ldots \ldots$

$4.3 .1 \quad$ Instâncias com possibilidade de atraso na entrega . . . . . . . . . . . . . . 53

4.3 .2 Instâncias sem possibilidade de atraso na produção . . . . . . . . . . . . . . 55

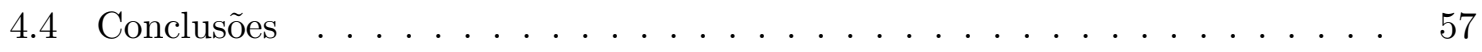

$\begin{array}{lll}5 \text { Conclusões } & 59\end{array}$ 


\section{Lista de Tabelas}

3.1 Resultados para instâncias de Trigeiro et al. [1989) adaptadas. . . . . . . . . 36

3.2 Resultados para instâncias heterogêneas de Muller et al.(2012) adaptadas. . 37

$3.3 \quad$ Resultados para instâncias homogêneas de Muller et al.[2012) adaptadas. . . 37

\begin{tabular}{|ll|l|l|}
\hline 3.4 & Resultados obtidos a partir de instâncias de & Toledo e Armentano $[2006)$ adap- \\
\hline
\end{tabular}

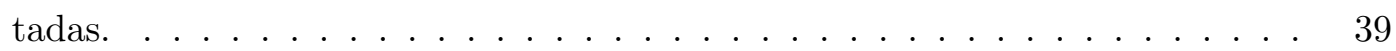

$4.1 \quad$ Resultados obtidos para as instâncias adaptadas de Trigeiro et al. [1989). . . 53

4.2 Resultados obtidos para as instâncias heterogêneas adaptadas de Muller et al.

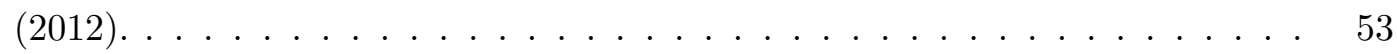

4.3 Resultados obtidos para as instâncias homogêneas adaptadas de Muller et al.

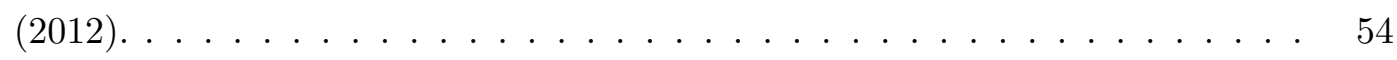

4.4 Resultados obtidos para as instâncias com múltiplas máquinas adaptadas de Toledo e Armentano (2006). . . . . . . . . . . . . . . . . . . . . . . 54

4.5 Resultados para as instâncias de Trigeiro et al. [1989). . . . . . . . . . . . 55

4.6 Resultados para as instâncias heterogêneas de Muller et al. [2012). . . . . . . . 55

4.7 Resultados para as instâncias homogêneas de Muller et al.[(2012). . . . . . . 56

\begin{tabular}{|ll|l}
\hline 4.8 & Resultados para as instâncias de & Toledo e Armentano \\
\hline
\end{tabular}

4.9 Resultados para as instâncias heterogêneas geradas a partir das instâncias de Muller et al. (2012). . . . . . . . . . . . . . . . 57

4.10 Resultados para as instâncias homogêneas geradas a partir das instâncias de

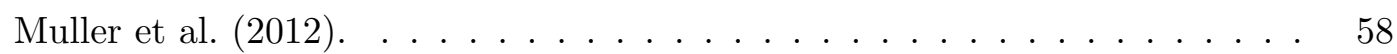





\section{Lista de Figuras}

3.1 Uma ilustração do processo de busca tabu. . . . . . . . . . . . . . . . . . 27

$3.2 \quad$ Etapas da heurística relax-and-fix. $\ldots \ldots \ldots \ldots \ldots \ldots$

3.3 Vizinhança de busca utilizada por Pedroso e Kubo (2005). . . . . . . . . . . . 30

$3.4 \quad$ Vizinhança de busca utilizada na busca tabu proposta. . . . . . . . . . . . . . 32

4.1 Processo de construção da solução inicial. . . . . . . . . . . . . . . . 45

4.2 Fluxograma da BTVA. . . . . . . . . . . . . . . . . . 52 



\section{Capítulo 1}

\section{Introdução}

Os sistemas de informações atuais propiciam novas possibilidades para um planejamento de produção mais sofisticado e eficiente, o qual deve utilizar os recursos disponíveis na indústria da melhor forma possível. Assim, o planejamento de produção tem como um de seus objetivos atingir as metas de produção com os menores custos possíveis. Dessa forma, o planejamento é uma estratégia fundamental para a empresa melhorar sua competitividade junto ao mercado.

De acordo com Karimi et al. (2003), o problema de dimensionamento de lotes (PDL) é um importante problema de decisão e planejamento de médio e, em alguns casos, de curto prazo. Esse é um problema clássico de pesquisa operacional que consiste em determinar a quantidade de cada produto a ser produzida e o momento em que a produção deve ocorrer, ou seja, o planejamento está relacionado a um horizonte de planejamento. O problema de dimensionamento de lotes pode ser encontrado em diferentes tipos de indústrias, tais como: indústrias têxteis (Silva e Magalhaes, 2006), de bebida (Ferreira et al., 2008), de alimentos (Toso et al., 2009), química (Selen e Heuts, 1990) e metalúrgicas (Camargo et al., 2012).

O PDL pode ser tratado como um problema discreto, em que a produção está inserida num horizonte de planejamento dividido em períodos, nos quais as demandas dos produtos são conhecidas e a produção excedente realizada em cada período pode ser estocada para os períodos posteriores. O objetivo é de cunho econômico, representado pelos custos de produção. Esses custos são comumente divididos em custo de estoque e de produção. O custo de produção se divide em custos de fabricação dos produtos e custos de preparação de máquina para a fabricação dos produtos.

Devido à sua importância teórica e prática, o problema de dimensionamento de lotes foi muito estudado. Dessa forma, diversos trabalhos de revisão e classificação do problema foram apresentados, dentre eles podemos citar Bahl et al. (1987), Karimi et al. (2003), Jans e Degraeve (2007), Buschkühl et al. (2008). Os primeiros trabalhos que enfocam o problema são de Manne (1958) e de Wagner e Whitin (1958) os quais abordam o PDL com um único produto sem restrições quanto à capacidade de produção para esse produto. Tratar o problema dessa forma é relativamente simples; entretanto, quando se adiciona a restrição de capacidade e múltiplos produtos no planejamento, o problema torna-se NP-Difícil (Bitran e Yanasse, 1982). 
O PDL possui muitas variações para representar características específicas de diferentes ambientes de produção. Essas características são inseridas no problema com objetivo de aproximá-lo da realidade do processo de produção, melhorando, assim, a qualidade das soluções obtidas. De modo geral, quanto mais próximos da realidade são os modelos, mais complexos se tornam e, quanto mais complexo é um problema, maiores são as dificuldades encontradas para resolvê-lo, pois, na maioria das vezes, o tempo computacional necessário para obter sua solução ótima é inviável na prática. Dessa forma, para esses problemas, justifica-se o desenvolvimento de métodos heurísticos para a sua resolução, pois, embora esses métodos não assegurem encontrar a solução ótima do problema, podem obter soluções de boa qualidade em tempo computacional aceitável. Recentemente, muitos pesquisadores têm se dedicado ao estudo da combinação de métodos exatos e heurísticos na construção de estratégias de solução que apresentem melhor desempenho na resolução de problemas de otimização combinatória (Maniezzo et al., 2009). Em especial, existem alguns trabalhos que combinam busca tabu com programação linear ou branch-and-bound. Blue e Bennett (1998) propõem um método de otimização global que combina busca tabu e programação linear; Bennell e Dowsland (2001) utilizam um método híbrido com busca tabu e programação linear para a resolução do problema de corte de estoque; Pedroso e Kubo (2005) apresentam um procedimento de busca tabu combinado com branch-and-bound e programação linear para a resolução de problemas de dimensionamento de lotes com máquinas paralelas. Flisberg et al. (2009) combinam programação linear e busca tabu para a resolução do problema de roteamento de veículos, enquanto que Woodcock e Wilson (2010) apresentaram uma heurística para a resolução do problema de designação generalizada, que combina busca tabu com o método branch-andbound.

O problema de dimensionamento de lotes abordado neste trabalho consiste em planejar a produção de múltiplos produtos em múltiplas máquinas durante um horizonte de planejamento finito. A demanda dos produtos é conhecida e pode ser atendida com atraso. São considerados os tempos de produção e de preparação para produção que utilizam recursos de uma capacidade produtiva limitada. O objetivo é de cunho econômico, visando minimizar a soma dos custos de produção, preparação para a produção, estoque dos produtos e atraso na entrega dos produtos.

Frente aos bons resultados obtidos na literatura por métodos híbridos combinando a metaheurística busca tabu, métodos baseados em branch-and-bound e técnicas de programação linear, nesta dissertação propomos um método híbrido para a resolução do problema estudado.

No texto que segue, no Capitulo 2, definimos o problema de dimensionamento de lotes e algumas de suas formulações. Também é apresentada uma revisão bibliográfica do problema de dimensionamento de lotes com foco nos primeiros trabalhos apresentados e nos mais recentes. No Capítulo 3 , apresentamos uma análise da influência da aleatoriedade sobre heurísticas busca tabu quando aplicadas ao problema estudado. No Capítulo 4 propomos um método híbrido que combina busca tabu, programação linear e branch-and-cut para a resolução do problema. No Capítulo 5, apresentamos as conclusões finais do trabalho, bem como as perspectivas para trabalhos futuros. 


\section{Capítulo 2}

\section{O problema de dimensionamento de lotes}

\subsection{Introdução}

Uma vez definido um horizonte de planejamento de produção, este pode ser dividido em períodos em que a demanda dos produtos e a quantidade de recursos disponíveis para a produção são conhecidas. O problema de dimensionamento de lotes consiste em determinar o quanto produzir de cada produto em cada período de forma a atender a demanda desses produtos.

Esse problema e suas variações são muito estudados. Pochet e Wolsey (2006) descrevem modelagens básicas e avançadas para o problema de dimensionamento de lotes com diferentes tipos de características como, por exemplo, capacidade de produção, tempos de preparação para produção e possibilidade de atendimento da demanda com atraso. Os autores também propõem um esquema de classificação para o problema e apresentam conceitos de planejamento de produção de curto, de médio e de longo prazo. Alguns métodos clássicos para a resolução desses problemas são descritos, entre eles os métodos: branch-and-bound, planos de corte e branch-and-cut. Também são apresentadas heurísticas como, por exemplo, relax-andfix e busca local. Boas revisões de modelos e técnicas de resolução para o problema podem ser encontradas em Quadt e Kuhn (2008), Buschkühl et al. (2008), Jans e Degraeve (2007), Brahimi et al. (2006), Karimi et al. (2003) e Drexl e Kimms (1997).

Neste trabalho, estudamos o problema de dimensionamento de lotes com múltiplos produtos e máquinas paralelas. Tempos e custos de preparação de máquina são considerados. A demanda dos produtos é conhecida a priori e pode ser atendida com atraso. Na Seção 2.2. detalhamos o problema abordado e definimos os modelos matemáticos que são utilizados no decorrer desta dissertação. Na Seção 2.3, apresentamos uma revisão bibliográfica para o problema de dimensionamento de lotes. 


\subsection{O problema estudado}

O problema aqui estudado envolve o planejamento de produção de múltiplos produtos cuja demanda é conhecida e pode ser atendida com atraso. São considerados custos de preparação, de estoque e de atraso, cuja soma deve ser minimizada. A produção pode ser realizada em múltiplas máquinas e consome recursos que são limitados.

Esse problema pode ser formulado de algumas maneiras distintas. Nesta dissertação, utilizaremos dois modelos matemáticos equivalentes os quais são descritos nas Seções 2.2.1 e 2.2 .2

\subsubsection{Modelo padrão}

O problema de dimensionamento de lotes com múltiplos produtos, máquinas paralelas, com restrições de capacidade pode ser modelado pelo seguinte problema inteiro misto:

$$
\begin{array}{lll}
\text { Min } & \sum_{t=1}^{T} \sum_{i=1}^{N} h_{i} I_{i t}+h b_{i} B_{i t}+\sum_{t=1}^{T} \sum_{i=1}^{N} \sum_{m=1}^{M} s_{i m} Y_{i m t} & \\
\text { s.a. } & \sum_{m=1}^{M} X_{i m t}+I_{i, t-1}-I_{i t}-B_{i, t-1}+B_{i t}=d_{i t} & i \in \mathcal{N} ; t \in \mathcal{T} ; \\
& \sum_{i=1}^{N}\left(b_{i m} X_{i m t}+f_{i m} Y_{i m t}\right) \leq C_{m} & m \in \mathcal{M} ; t \in \mathcal{T} ; \\
& X_{i m t} \leq l s_{i m} Y_{i m t} & i \in \mathcal{N} ; m \in \mathcal{M} ; t \in \mathcal{T} ; \\
I_{i 0}=0, B_{i 0}=0 & i \in \mathcal{N} ; \\
I_{i t} \geq 0, B_{i t} \geq 0 & i \in \mathcal{N} ; t \in \mathcal{T} ; \\
Y_{i m t} \in\{0,1\}, X_{i m t} \geq 0 & i \in \mathcal{N} ; m \in \mathcal{M} ; t \in \mathcal{T} ;
\end{array}
$$

em que:

Índices e conjuntos:

- $N$ : Número de produtos;

- $M$ : Número de máquinas;

- $T$ : Número de períodos;

- $\mathcal{N}:\{1, \ldots, N\}$ : Conjunto de produtos;

- $\mathcal{M}:\{1, \ldots, M\}$ : Conjunto de máquinas;

- $\mathcal{T}:\{1, \ldots, T\}$ : Conjunto de períodos.

Parâmetros:

- $s_{i m}$ : Custo de preparação para a produção do produto $i$ na máquina $m$;

- $h_{i}$ : Custo unitário de estoque do produto $i$;

- $h b_{i}$ : Custo unitário de atraso na entrega do produto $i$;

- $d_{i t}$ : Demanda do produto $i$ no período $t$;

- $b_{i m}$ : Tempo de processamento do produto $i$ na máquina $m$; 
- $f_{i m}$ : Tempo de preparação para a produção do produto $i$ na máquina $m$;

- $C_{m}$ : Capacidade de produção em cada período na máquina $m$ (em unidades de tempo);

- $l s_{i m}$ : É o limitante superior para a produção do produto $i$ na máquina $m$, que é igual ao $\min \left\{C_{m}-f_{i m}, \sum_{t=1}^{T} d_{i t}\right\}$.

Variáveis:

- $X_{\text {imt }}$ : Quantidade produzida do produto $i$ na máquina $m$ no período $t$;

- $Y_{i m t}$ : Variável binária que assume valor 1 se o produto $i$ for produzido na máquina $m$ no período $t$ e assume o valor 0 (zero) caso contrário;

- $I_{i t}$ : Número de unidades do produto $i$ em estoque no final do período $t$;

- $B_{i t}$ : Número de unidades do produto $i$ em atraso no final do período $t$.

No modelo (1) - (7), a função objetivo (1) visa minimizar a soma dos custos de estoque, de atraso na entrega dos produtos e de preparação para produção,. As restrições (2) asseguram que a demanda de cada produto $i$ no período $t$ é atendida pela produção do produto no próprio período, por estoque, ou atendida com atraso. As restrições (3) indicam que a capacidade disponível para a produção em cada máquina é limitada e compartilhada entre os produtos fabricados num mesmo período. As restrições (4) garantem a incidência do custo e do tempo de preparação quando há produção do produto $i$ na máquina $m$ no período $t$, ou seja, quando $X_{i m t}$ é positivo. Os estoques e atrasos iniciais são, sem perda de generalidade, considerados nulos em (5) (Johnson e Montgomery, 1974). A não negatividade das variáveis $I_{i t}$ e $B_{i t}$ é assegurada pelas restrições (6). O domínio das variáveis de produção é definido pelas restrições (7).

\subsubsection{Reformulação baseada em Krarup e Bilde (1977)}

O modelo (1)-(7) possui relaxação linear pobre (Denizel et al., 2008). Na literatura, foram estudadas outras formulações do problema, abordando o caso com uma única máquina. Dessas formulações, duas são as mais estudadas na literatura. A primeira, que utiliza ideias de localização de facilidades, foi proposta por Krarup e Bilde (1977), já a segunda, proposta por Eppen e Martin (1987), formula o problema utilizando ideias de caminho mínimo. Denizel et al. (2008) realizam uma análise das propostas apresentadas por Krarup e Bilde (1977) e Eppen e Martin (1987). Através do método de redefinição de variáveis, os autores provam que as relaxações lineares de ambos os problemas possuem a mesma região factível. Ainda, foi ressaltado que as formulações têm desempenho similar na resolução do problema. Dessa forma, adotamos, sem perda de generalidade, a formulação proposta em Krarup e Bilde (1977) para nosso problema.

A ideia principal da reformulação é desagregar a variável de produção $(X)$, acrescentando a ela o período em que o produto será entregue. Então, a nova variável é definida como:

- $X_{\text {imtk }}$ : Quantidade produzida do produto $i$ na máquina $m$ no período $t$ para atender a demanda do período $k$. 
Note que é possível extrair da variável $X$ as informações sobre o estoque e sobre atrasos na entrega da demanda. Realizando as adaptações pertinentes, a reformulação matemática do problema é dada por:

$$
\begin{array}{lll}
\text { Min } & \sum_{i=1}^{N} \sum_{m=1}^{M} \sum_{t=1}^{T} \sum_{r=1}^{t-1}(t-r) h_{i} X_{i m t r}+ & \\
& \sum_{i=1}^{N} \sum_{m=1}^{M} \sum_{t=1}^{T} \sum_{r=t+1}^{T}(r-t) h b_{i} X_{i m t r} & +\sum_{i=1}^{N} \sum_{m=1}^{M} \sum_{t=1}^{T} s_{i m} Y_{i m t} \\
\text { s.a. } & \sum_{m=1}^{M} \sum_{t=1}^{T} X_{i m t k}=d_{i k} & i \in \mathcal{N} ; k \in \mathcal{T} ; \\
& \sum_{i=1}^{N}\left(\sum_{k=1}^{T}\left(b_{i m} X_{i m t k}\right)+f_{i m} Y_{i m t}\right) \leq C_{m} & t \in \mathcal{T} ; m \in \mathcal{M} ; \\
& X_{\text {imtk }} \leq d_{i k} Y_{i m t} & i \in \mathcal{N} ; m \in \mathcal{M} ; t \in \mathcal{T} ; \\
& X_{\text {imtk }} \geq 0 ; Y_{i m t} \in\{0,1\} & i \in \mathcal{N} ; m \in \mathcal{M} ; t \in \mathcal{T} ; k \in \mathcal{T} ;
\end{array}
$$

No modelo (8) - (12), a função objetivo (8) visa minimizar a soma de suas três parcelas as quais representam, respectivamente, a soma dos custos de estoque, as somas dos custos de atraso para a produção dos produtos e a soma dos custos de preparação para a produção. As restrições (9) asseguram que a demanda de cada produto $i$ no período $k$ será atendida. As restrições (10) indicam que a capacidade disponível para a produção em cada máquina é limitada. As restrições (11) garantem a incidência do custo e do tempo de preparação quando há produção do produto $i$ na máquina $m$ no período $t$. O domínio das variáveis de produção é definido pelas restrições (12).

Uma das vantagens de utilizar essa formulação (8-12) é o fato de sua relaxação linear ser mais próxima da envoltória convexa quando comparada à formulação anterior (1-7), pois $d_{i k}$ é um bom limitante para $X_{i m t k}$, então $Y_{i m t}$ fica mais próximo de 1 na solução relaxada. A desvantagem é que, ao realizarmos a desagregação da variável $X$, criamos $T$ vezes mais variáveis reais para o problema. Portanto, essa desagregação aumenta a dimensão do problema, o que pode tornar a resolução de instâncias muito grandes inviável.

\subsection{Revisão bibliográfica}

O problema de dimensionamento de lotes é estudado há mais de cinco décadas. Diversas abordagens já foram propostas para sua modelagem. Também, foram propostos alguns métodos exatos e muitos heurísticos para sua resolução, o que se justifica por sua dificuldade de resolução. Florian et al. (1980) apresentam uma revisão dos algoritmos polinomiais para a resolução do problema de dimensionamento de lotes com um único produto e sem restrições de capacidade. Os autores provam que, sob algumas características da demanda e dos custos de preparação de máquina, produção e estoque, o problema pode ser NP-difícil ou pertencer à classe P. Posteriormente, Bitran e Yanasse (1982) estudam o problema com restrições de capacidade mostrando também que, dependendo de algumas características, esse pode ser NP-difícil ou pertencer à classe $\mathrm{P}$. Os autores também provam que os problemas com um único produto que são resolvidos em tempo polinomial se tornam NP-difíceis quando 
é adicionado ao planejamento um segundo produto. Maes et al. (1991) mostram que, para problemas nos quais o tempo de preparação é não nulo, encontrar uma solução factível é um problema NP-completo. Provam também que, para problemas com tempos de preparação nulos, o problema de encontrar uma solução factível pertence à classe P.

Com o objetivo de tornar a revisão mais simples, os trabalhos estão divididos da seguinte maneira:

- Problemas com uma única máquina

- Um único produto;

- Múltiplos produtos com restrições de capacidade e custos de preparação;

- Múltiplos produtos com restrições de capacidade, custos e tempos de preparação para produção;

- Problemas com múltiplas máquinas e múltiplos produtos.

Como o problema de dimensionamento de lotes foi amplamente estudado na literatura e boas revisões sobre o tema estão disponíveis nesta revisão bibliográfica, restringimo-nos aos primeiros trabalhos que abordam cada variação do problema discutida acima e aos trabalhos mais recentes.

\subsubsection{Problemas com uma única máquina e um único produto}

Wagner e Whitin (1958) propuseram o primeiro método ótimo para resolução do problema de dimensionamento de lotes com um único produto e sem restrições de capacidade. Os autores apresentam um algoritmo de programação dinâmica com complexidade polinomial $O\left(T^{2}\right)$ ( $T$ é o número de períodos) para a resolução do problema. O algoritmo consiste em encontrar o caminho de custo mínimo em um grafo direcionado que representa o problema. Nos anos 90, Aggarwal e Park (1993), Wagelmans et al. (1992) e Federgruen e Tzur (1991) desenvolveram de forma independente métodos de complexidade $O(T \log (T))$ para a resolução do problema. Esta complexidade é reduzida para $O(T)$ quando o custo unitário de produção não decresce ao longo do horizonte de produção.

Um modelo que permite o atendimento da demanda com atraso foi explorado por Zangwill (1966). O autor apresenta um algoritmo baseado em programação dinâmica com complexidade $O\left(T^{2}\right)$ para a resolução desse problema. Zangwill (1969) analisa duas formulações distintas: a primeira permite a produção de um único produto e a segunda permite a produção de múltiplos produtos. Ambas as formulações permitem o atraso na entrega dos produtos. O autor mostra que os dois modelos podem ser representados por uma rede de fluxo mínimo com uma única fonte. Utilizando a representação, são desenvolvidos métodos de programação dinâmica para a resolução dos problemas analisados.

Uma reformulação para o problema sem restrições de capacidade é proposta por Krarup e Bilde (1977). A nova formulação é baseada no problema de localização de facilidades e consiste em desagregar as variáveis de produção de cada período. Apesar de o modelo proposto possuir um maior número de variáveis, sua relaxação linear é mais próxima da 
envoltória convexa do problema quando comparada à da relaxação linear das formulações anteriores. Esse fato permite a obtenção de limitantes provenientes da relaxação linear de melhor qualidade, além de uma integralidade maior das variáveis inteiras na relaxação linear. A formulação pode ser estendida para outras variações do problema.

Florian e Klein (1971) abordam o problema considerando um limite sobre a capacidade de produção. Os autores caracterizam os pontos extremos nos quais a produção deve ser zero ou toda a capacidade de produção do período. Isso pode ocorrer em, no máximo, um período. Os autores utilizam essa propriedade para desenvolver um algoritmo baseado em programação dinâmica para resolver o problema. Uma generalização foi proposta por Love (1973), na qual a quantidade de estoque também é limitada.

Uma revisão sobre problemas de dimensionamento de lotes com um único produto englobando os casos com e sem restrições de capacidade pode ser encontrada em Wolsey (1995) e Brahimi et al. (2006). Os autores apresentam diversas modelagens para os problemas e extensões dos mesmos. Além disso, é realizada uma análise sobre diversas técnicas de solução dos problemas.

\subsubsection{Múltiplos produtos com restrições de capacidade e custos de prepa- ração para produção}

Barany et al. (1984) foram um dos primeiros autores a tratar o problema de dimensionamento de lotes com restrições de capacidade e custos de preparação para a produção. Os autores propuseram um método de solução em duas fases. Na primeira, é executado o método de planos de corte a fim de obter uma melhor aproximação da envoltória convexa do problema. Em seguida, é aplicado um método do tipo branch-and-bound. Foram realizados testes computacionais com instâncias de até 20 produtos e 13 períodos.

Evans (1985) utiliza uma redefinição de variáveis para reformular o modelo como um problema de fluxo em redes. Um método do tipo branch-and-bound para sua resolução foi proposto. Ele é aplicado de forma exata para instâncias com até 4 períodos e 6 produtos e de forma aproximada para instâncias com até 6 períodos e 8 produtos.

Eppen e Martin (1987) apresentam uma nova formulação baseada no problema de caminho mínimo. O novo modelo, assim como o proposto em Krarup e Bilde (1977), apresenta uma relaxação linear mais próxima da envoltória convexa do problema quando comparada à relaxação linear das formulações inicialmente propostas. Em contrapartida, apresenta um número maior de variáveis. Testes computacionais foram realizados utilizando diferentes softwares comerciais; para problemas com até 200 produtos e 10 períodos, foi obtida a solução ótima. Para problemas maiores, um método heurístico baseado no método ótimo foi aplicado.

Hindi (1995) propôs um método baseado em branch-and-bound, utilizando geração de colunas e redefinição de variáveis para resolver o problema. A estratégia utilizada resulta em bons limitantes inferiores. Testes computacionais foram realizados, utilizando as instâncias de Eppen e Martin (1987). Os resultados obtidos mostraram que, para algumas instâncias, o método proposto obtém soluções melhores. Os autores também utilizaram o método de forma heurística no qual também obtiveram bons resultados. 
Uma revisão para o problema de dimensionamento de lotes com múltiplos produtos e tempo de preparação nulo foi realizada em Drexl e Kimms (1997). Neste trabalho os autores apresentam algumas variações do problema ressaltando suas características. Também são apresentadas revisões dos principais métodos exatos e heurísticos que foram desenvolvidos para os problemas abordados.

\subsubsection{Múltiplos produtos com restrições de capacidade, custo e tempo para preparação}

O tempo de preparação de máquina, como destaca Trigeiro (1987), não deveria ser representado simplesmente pelos custos de produção, pois pode influenciar de forma significativa a utilização da capacidade de produção. Quando o tempo de preparação para produção não é considerado, é possível encontrar uma solução que, ao contabilizarmos os tempos que essas preparações utilizam, torna-se inviável.

Esse problema é de difícil resolução (Maes et al., 1991), portanto poucos métodos exatos foram propostos para sua resolução. Diaby et al. (1992) propuseram um método branchand-bound que utiliza relaxação lagrangeana a fim de encontrar limitantes inferiores para o problema com possibilidade de horas extras e sem custo de preparação de máquina. Duas relaxações distintas são utilizadas: a primeira consiste em relaxar a restrição de capacidade obtendo subproblemas que podem ser resolvidos em tempo polinomial pelo método de Wagner e Whitin (1958); a segunda consiste em relaxar as restrições de demanda obtendo, assim, subproblemas da mochila, que, apesar de serem classificados como NP-difícil (Martello e Toth, 1990), existem diversas abordagens eficientes para sua resolução (Martello e Toth, 1977; Pisinger, 2000). Souza e Armentano (1994) propõem um algoritmo ótimo de decomposição cruzada para a resolução do problema considerando a possibilidade da realização de horas extras. Armentano et al. (1999) apresentam um modelo matemático para o problema baseado em fluxos em redes generalizado. Para a resolução do novo modelo, os autores propõem um método do tipo branch-and-bound.

O primeiro trabalho que apresentou um método para a resolução do problema com tempos de preparação para produção é de Trigeiro et al. (1989). Os autores propõem uma heurística baseada em relaxação lagrangeana para a resolução do problema. O método consiste em dualizar as restrições de capacidade. Os subproblemas obtidos são resolvidos de forma exata pelo método proposto por Wagner e Whitin (1958) e, para resolver o problema relaxado, é utilizado o método do subgradiente. A cada passo do método, uma heurística de factibilização é aplicada para buscar soluções inteiras factíveis. Um conjunto de problemas testes, com até 24 produtos e 30 períodos, foi proposto para os quais as soluções encontradas estão a menos de 8,5\% do ótimo. Em Lozano et al. (1991), é apresentado um algoritmo similar: as diferenças estão no processo de factibilização de solução e na garantia de acréscimo na função do problema relaxado, o que garante a convergência do método em um número finito de iterações.

Em Denizel e Süral (2006), é apresentada uma comparação entre as principais modelagens para o problema, ressaltando os pontos positivos e negativos de cada formulação. Os 
autores fazem uma avaliação da relaxação linear de cada modelagem e desenvolvem algumas heurísticas para a resolução do problema, utilizando o método branch-and-bound e a relaxação linear.

Caserta e Rico (2009) propuseram uma meta-heurística baseada em relaxação lagrangeana para o problema. Neste trabalho, a restrição de capacidade é relaxada originando uma variedade de subproblemas que são resolvidos por uma adaptação do algoritmo apresentado em Caserta et al. (2008). O problema, então, é resolvido pelo método do subgradiente. A cada passo do método, é aplicada uma heurística de factibilização gulosa. Testes computacionais foram realizados utilizando as instâncias de Trigeiro et al. (1989) e instâncias geradas aleatoriamente para as quais os desvios encontrados foram menores que $2,4 \%$.

Recentemente, Süral et al. (2009) desenvolvem uma heurística para a resolução do problema utilizando a formulação baseada em Krarup e Bilde (1977). A heurística consiste em dualizar as restrições de atendimento de demanda, obtendo subproblemas da mochila. Assim, o problema é resolvido pelo método do subgradiente. Foram realizados testes computacionais utilizado as instâncias de Trigeiro et al. (1989) modificadas. Os resultados apresentados mostram-se melhores que os obtidos em Trigeiro et al. (1989) nos casos em que o custo de preparação de máquina não está presente na função objetivo.

Muller et al. (2012) propõem uma heurística ALNS (adaptative large neighborhood search) para resolver o problema. Testes computacionais foram realizados utilizando as instâncias de Trigeiro et al. (1989) adaptadas como em Süral et al. (2009). Além disso, os autores geraram testes aumentando o número de períodos das instâncias originais com o objetivo de aumentar a dificuldade de resolução do problema. Os resultados obtidos se mostraram competitivos quando comparados aos do solver CPLEX 12.1 e ao método proposto por Süral et al. (2009).

Uma revisão mais ampla dos métodos de solução aplicados ao problema pode ser encontrada em Quadt e Kuhn (2008), Buschkühl et al. (2008), Jans e Degraeve (2007) e Karimi et al. (2003). Nesses trabalhos, são compilados os mais importantes modelos matemáticos e técnicas de solução aproximada para problemas de dimensionamento de lotes com múltiplos produtos e tempo de preparação não nulo das últimas quatro décadas. Entre as heurísticas abordadas no trabalho, estão as do tipo lagrangeana, de decomposição e agregação, metaheurísticas e heurísticas gulosa.

\subsubsection{Problemas com múltiplas máquinas e múltiplos produtos}

Sung (1986) aborda o problema sem restrições de capacidade e sem considerar o tempo de preparação de máquina. Para a sua resolução, o autor propôs um método exato baseado em programação dinâmica com complexidade $O\left(M \times T^{2}\right)$.

Lasdon e Terjung (1971) propõem uma heurística com máquinas idênticas sem considerar o tempo de preparação de máquina. Os autores abordam o problema de produção em que apenas um produto pode ser produzido em cada máquina por período.

Um método heurístico para a resolução do problema com tempos de preparação para a produção e demanda continua ao longo do horizonte de produção foi proposto por Carreno (1990). Em cada período, apenas um tipo de produto pode ser fabricado em cada máquina 
e a produção de produtos que tenham disponibilidade em estoque não é permitida.

Sabbag (1993) propõe uma heurística para a resolução do problema considerando tempo de preparação de máquina e máquinas paralelas distintas. A heurística possui basicamente três passos. No primeiro, é construída uma solução inicial para o problema utilizando a relaxação linear do mesmo; em seguida, é executado o passo de factibilização dessa solução. Quando uma solução factível é obtida, é aplicado um passo de melhoria.

Pedroso e Kubo (2005) apresentam uma heurística híbrida que combina a heurística busca tabu e uma variação da heurística relax-and-fix para a resolução do problema. Para os testes computacionais, os autores geram instâncias aleatoriamente, de até 12 produtos, 12 períodos e 1 máquina, com base em problemas reais e utilizam instâncias já existentes no repositório online LOTSIZELIB (Belvaux e Wolsey, 1999). Testes computacionais foram realizados e os resultados mostraram que a busca tabu proposta pelos autores obtém soluções a menos de $5,2 \%$ da otimalidade.

Toledo e Armentano (2006) propõem uma heurística lagrangeana para a resolução do problema. Este método é baseado na relaxação lagrangeana das restrições de capacidade e no método dos subgradientes. Testes computacionais foram realizados utilizando instâncias de Trigeiro et al. (1989) com uma máquina e com instâncias com múltiplas máquinas geradas pelos autores com até 6 máquinas, 50 produtos e 18 períodos. 


\section{Capítulo 3}

\section{Análise do impacto da aleatoriedade sobre heurísticas busca tabu hídridas}

Pedroso e Kubo (2005) propuseram uma busca tabu para a resolução de problemas de dimensionamento de lotes com máquinas paralelas. O problema abordado é do tipo big bucket, no qual é permitido que cada máquina produza mais de um produto por período e, consequentemente, é possível realizar mais de uma preparação na mesma máquina por período. Nesse trabalho, os autores também consideram custos de preparação e a possibilidade de atendimento da demanda com atraso.

A busca tabu proposta pelos autores utiliza o método relax-and-fix para gerar uma solução inicial. Então, o processo de busca tem início a partir dessa solução. Ao atingir um mínimo local, uma etapa de reinicio da busca é realizada. Nesta etapa, são escolhidas aleatoriamente variáveis para serem fixas e as demais são redefinidas pelo método relax-and-fix.

O principal objetivo de estudo deste capítulo é mostrar que o método de busca tabu não precisa recorrer à aleatoriedade, como realizado em Pedroso e Kubo (2005), para encontrar soluções de boa qualidade para o PDL abordado. Para tanto, baseados no trabalho dos autores, propomos dois métodos de busca tabu para resolver o problema de dimensionamento de lotes. O primeiro é uma busca tabu pura, ou seja, sem intensificação e diversificação, já o segundo é uma busca tabu com intensificação e diversificação incorporadas ao processo de busca. Testes computacionais foram realizados para comparar os métodos.

Este capítulo está organizado da seguinte forma: na Seção 3.1, são discutidas as heurísticas básicas utilizadas nos métodos de solução; na Seção 3.2 , é apresentado o método de Pedroso e Kubo (2005) e, na Seção 3.3 , propomos uma heurística determinística baseada no trabalho de Pedroso e Kubo (2005). Para avaliar o desempenho das heurísticas propostas, na Seção 3.4 são apresentados testes computacionais. E, por fim, na Seção 3.5 são apresentadas as conclusões deste capítulo. 


\subsection{Conceitos básicos}

Nesta seção, são apresentados conceitos básicos das heurísticas de busca e construção de solução utilizados pelos métodos heurísticos propostos. Nas Subseções 3.1.1 e 3.1.2, são apresentadas, de forma geral, as heurísticas busca tabu e relax-and-fix.

\subsubsection{Busca tabu}

A busca tabu é uma meta-heurística muito utilizada para resolução de problemas de otimização combinatória. Essa estratégia foi proposta por Glover (1989, 1990) e consiste basicamente em buscar soluções de melhor qualidade para um problema numa vizinhança de uma dada solução .

A vizinhança (ou região) de uma dada solução pode ser definida como um conjunto de soluções factíveis para o problema que respeitam algumas restrições como, por exemplo: a) similaridade com a solução corrente; e b) proibição da ocorrência de determinadas situações.

Antes de descrevermos a busca tabu, vamos definir o que é uma busca local. Dada uma solução inicial $x$, a busca local se caracteriza por escolher dentre as soluções pertencentes a uma dada vizinhança de $x(V(x))$ uma nova solução $\bar{x}$. Usualmente são utilizadas duas estratégias para a escolha de $\bar{x}$ :

- Estratégia de descida: escolhemos a primeira solução visitada na vizinhança de busca $(V(x))$ que for de melhor qualidade que a solução atual $(x)$;

- Estratégia de máxima descida: escolhemos a solução de melhor qualidade da vizinhança de busca $(V(x))$.

Cada passo desse processo de busca é chamado de movimento. A busca chega ao fim quando, na vizinhança de uma solução, não é encontrado nenhum movimento que leve a uma solução de melhor qualidade para o problema. Logo, estamos em um mínimo local da busca. O Algoritmo 4 ilustra a busca local com a estratégia de máxima descida.

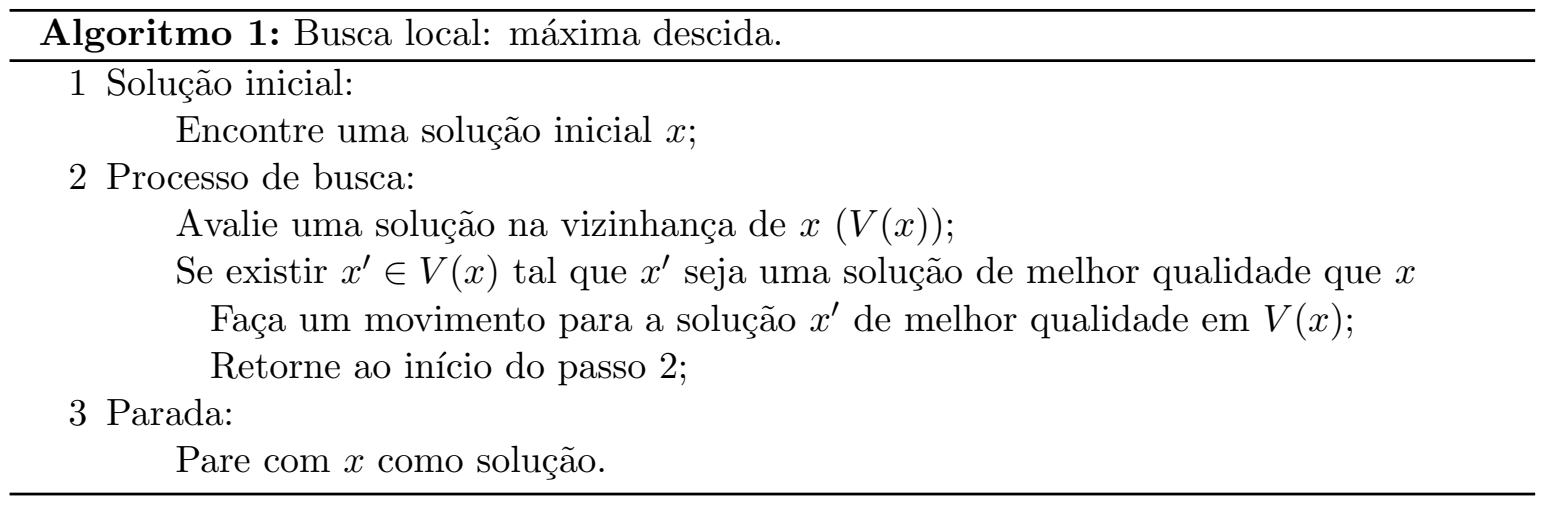

Uma das características que diferem a busca tabu da busca local é a possibilidade de a busca superar mínimos locais. Isso significa que podemos realizar movimentos que pioram a qualidade da solução, com esperança de que, no decorrer da busca, possamos chegar a um outro mínimo local de melhor qualidade que outros já visitados. A Figura 3.1 ilustra os 
movimentos de uma busca tabu. Note que em (b) é atingido um mínimo local, e que em (c) e em (d) a busca piora o valor da solução atual em direção a um novo mínimo local, que é atingido em (f).

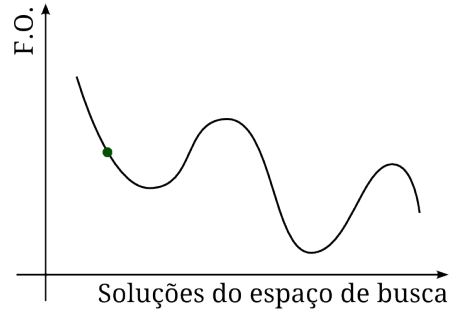

(a)

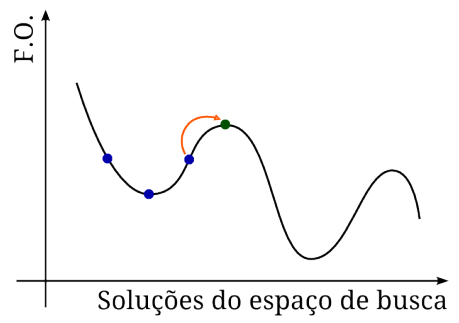

(d)

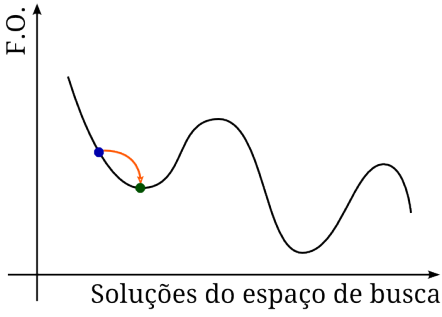

(b)

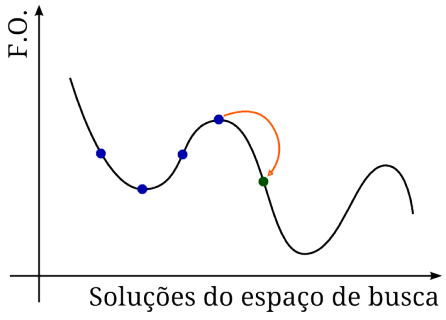

(e)

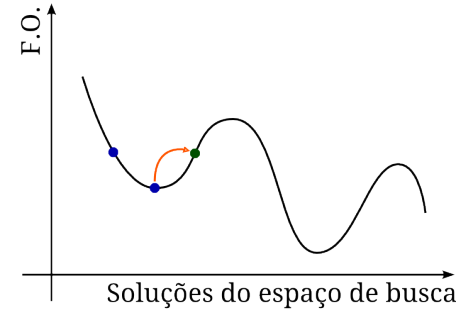

(c)

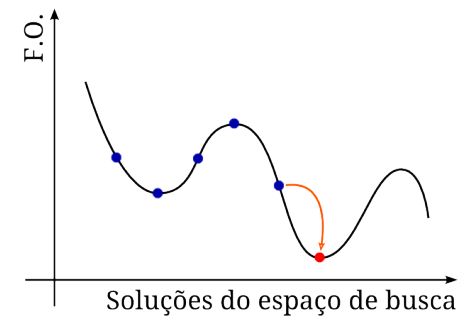

(f)

Figura 3.1: Uma ilustração do processo de busca tabu.

Quando realizamos um movimento, desejamos melhorar a qualidade da solução obtida ou, ao menos, piorá-la o mínimo possível. Logo, é natural que, ao realizarmos um movimento que piora a qualidade da solução corrente, a busca guie o próximo movimento a voltar ao mínimo local anterior, este fato é caracterizado como ciclagem. A ciclagem compromete o processo de busca por novas soluções e, dessa forma, é necessário incorporar um elemento restritivo à busca que torne alguns movimentos tabu (ou proibidos), prevenindo a ciclagem, o que permite ao processo de busca explorar novas regiões. Esses elementos restritivos são chamados de restrições tabu.

Quando um movimento é realizado, é criada uma restrição tabu com os atributos desse movimento que impede a busca de desfazê-lo. O conjunto com todas as restrições tabu é denominado lista tabu.

Por outro lado, com o decorrer do processo de busca, o acúmulo de elementos na lista tabu pode tornar a região de busca muito limitada ou até mesmo vazia. Para contornar essa dificuldade, cada restrição tabu somente permanece na lista tabu por um número prédeterminado de iterações (este número de iterações não é necessariamente o mesmo para todas as restrições tabu da lista).

Com a finalidade de tornar a busca ainda menos restritiva, é definido um critério de aspiração o qual permite, sob algumas condições, que um movimento seja realizado mesmo que este pertença à lista tabu. Frequentemente, as condições utilizadas para o critério de aspiração são:

- o movimento levará o processo a obter uma solução de melhor qualidade que qualquer outra já visitada durante o processo de busca; 
- todas as soluções presentes na vizinhança de uma dada solução estão na lista tabu.

As restrições tabu e o critério de aspiração definem a base da função de memória de curto prazo da busca tabu. Essa função é responsável por realizar a busca por soluções de maneira a sempre tentar obter uma melhor solução sujeita a uma dada região (vizinhança de solução). O Algoritmo 2 resume a busca tabu somente com memória de curto prazo.

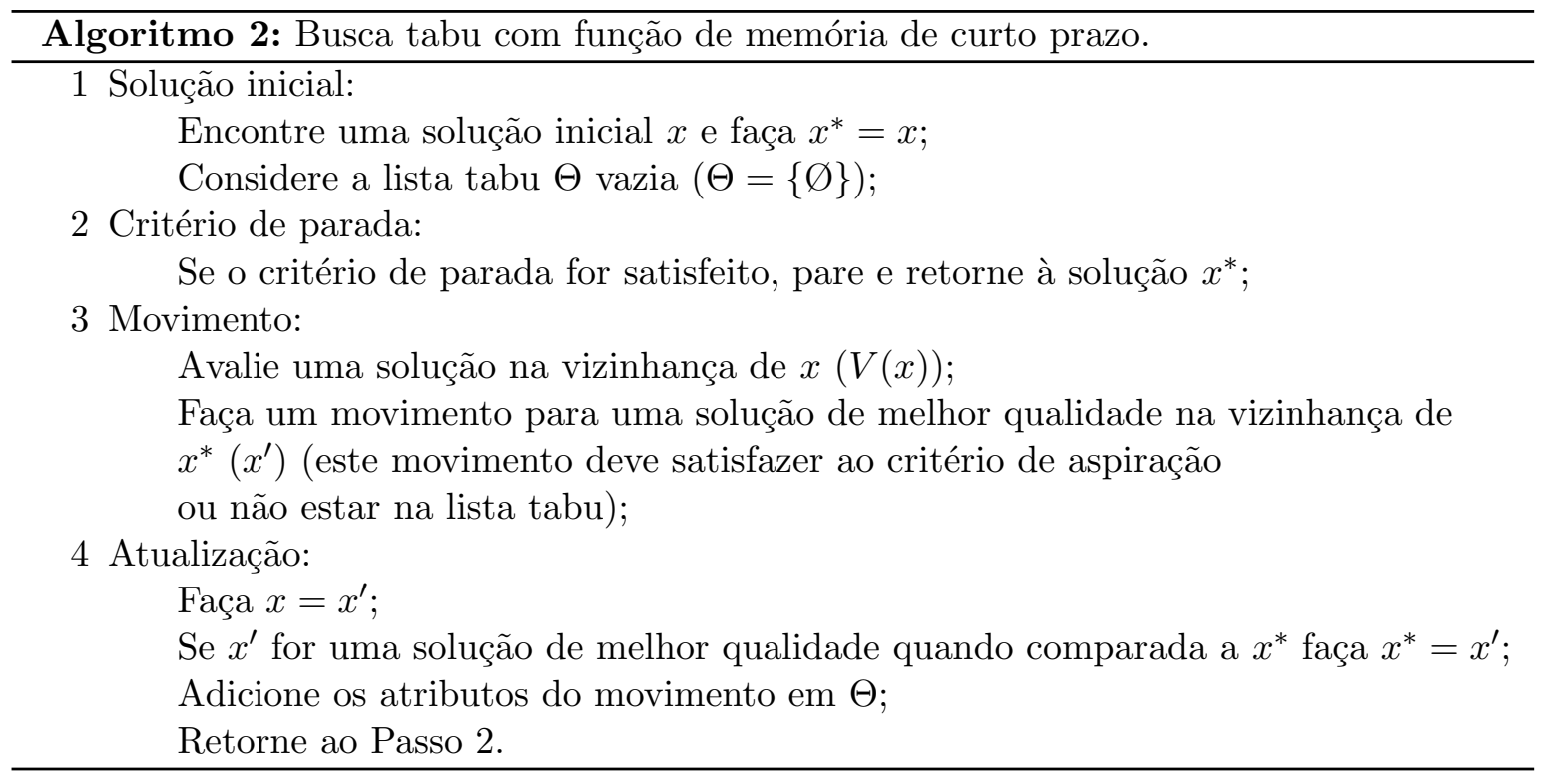

Diversos critérios de parada podem ser utilizados na busca tabu, os mais comuns são definir um número máximo de iterações ou um tempo limite para a execução.

Muitas vezes, utilizar somente a memória de curto prazo faz com que o processo leve muito tempo para encontrar soluções de boa qualidade. Para melhorar a eficiência da busca, em muitas aplicações é necessário o uso de funções de memória de longo prazo as quais são responsáveis por promover a intensificação local e a diversificação global da solução.

Mais especificamente, a estratégia de intensificação consiste em retornar a busca para regiões consideradas promissoras que foram parcialmente visitadas pelo processo de busca. Isso é realizado analisando características das soluções encontradas durante um determinado período do processo de busca e, então, procurando por soluções que exibam características similares às dessas soluções.

Em contraste com a intensificação, o objetivo da diversificação é explorar novas regiões, ou seja, é buscar soluções que difiram das encontradas durante um determinado período do processo de busca. O processo é realizado de maneira inversa ao processo de intensificação, ou seja, é feita uma análise das características das soluções encontradas durante o processo de busca e, então, procura-se por soluções que tenham características distintas das encontradas até o momento, gerando um novo ponto de partida para a busca.

\subsubsection{Relax-and-fix}

O método relax-and-fix é bastante utilizado na literatura para solucionar problemas de otimização combinatória, em especial, problemas de dimensionamento de lotes (James e 
Almada-Lobo, 2011; Ferreira et al., 2010; Wu e Shi, 2009; Beraldi et al., 2008; Pedroso e Kubo, 2005). De modo geral, a heurística propõe solucionar o problema em etapas, sendo que, a cada etapa, é resolvido de forma exata um subproblema derivado do problema original. Para tanto, as variáveis inteiras do problema são divididas em três grupos: variáveis fixas, variáveis inteiras não fixas (livres) e variáveis inteiras linearmente relaxadas. Em cada etapa do método, temos um subproblema em que cada variável inteira do problema deve pertencer a um desses conjuntos. Ao fim de cada etapa, é obtida uma solução para o subproblema a ela associado. Assim, são fixadas as variáveis inteiras livres no valor da solução encontrada. Então, do conjunto de variáveis inteiras relaxadas, um novo subconjunto de variáveis (uma partição) é escolhido para ser composto por inteiras livres. Esse procedimento é realizado até que todas as variáveis inteiras do problema original tenham sido fixadas. A Figura 3.2 ilustra a dinâmica da técnica.
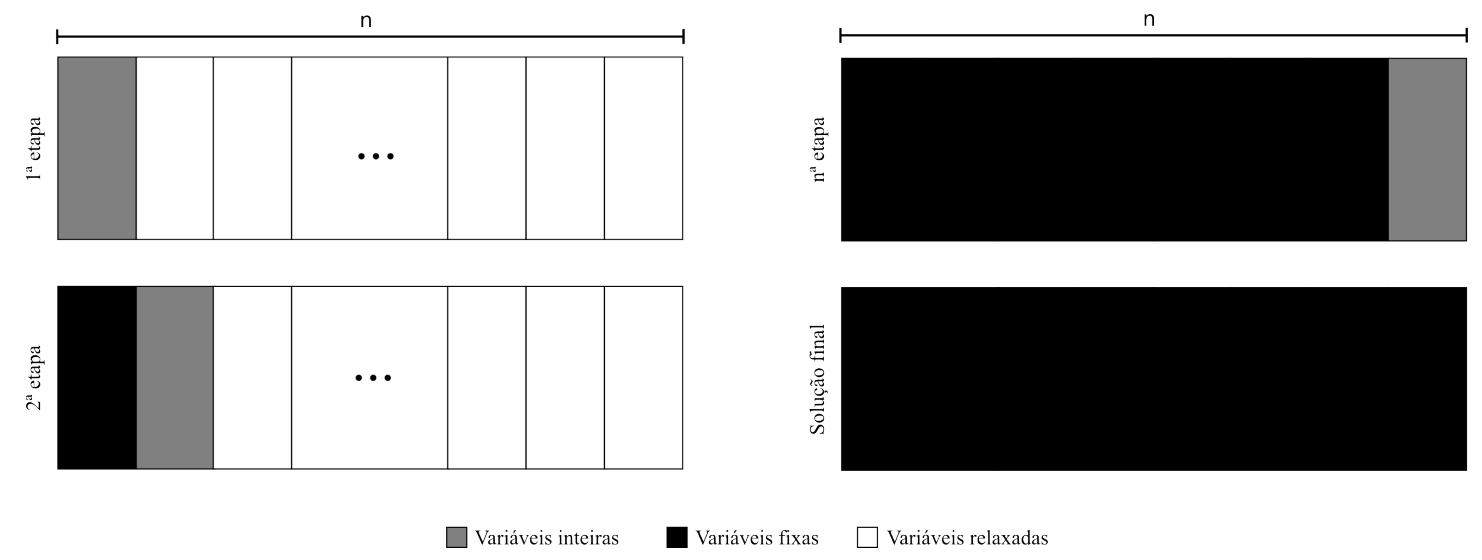

Figura 3.2: Etapas da heurística relax-and-fix.

\subsection{Heurística híbrida de Pedroso e Kubo (2005)}

Pedroso e Kubo (2005) propuseram uma busca tabu híbrida, denominada HTS (Hybrid Tabu Search), para solução do problema de dimensionamento de lotes com uma ou mais máquinas. O método híbrido consiste em uma busca tabu somente com estruturas de memória de curto prazo. A heurística relax-and-fix é utilizada para gerar novos pontos de partida e prover a inicialização da busca tabu.

O método pode executar diversas vezes a heurística relax-and-fix e, assim, é importante que ela seja capaz de encontrar soluções factíveis independentemente da ordem de escolha das partições. Dessa forma, os autores permitem o atendimento da demanda com atraso, mesmo no último período, podendo postergar a produção para períodos que não estão contidos no horizonte de planejamento. Com isso, sempre existirá uma solução factível independentemente da ordem de escolha das partições.

As partições da heurística relax-and-fix são definidas por um produto, um período e todas as máquinas. A ordem de escolha de qual partição será inteira a cada etapa é feita da seguinte maneira: 
- Sequencialmente em relação aos períodos;

- Em cada período, a escolha sobre qual produto terá as variáveis consideradas inteiras é aleatória.

O método exato utilizado para a resolução do subproblema resultante a cada etapa é o branch-and-cut, utilizado do pacote GLPK.

A partir da solução inicial obtida (y), os autores aplicam a busca tabu. A vizinhança de busca $V(y)$ de uma dada solução factível $y$ adotada é descrita a seguir.

Seja $y$ o vetor que representa a ocorrência ou não da preparação de máquina, representado, respectivamente, por um e zero. Considere que cada coordenada do vetor y é dada por $y_{p m t}$, em que $p \in\{1 \ldots N\}, m \in\{1 \ldots M\}$ e $t \in\{1 \ldots T\}$. Com isso, os autores definem os conjuntos $S_{p t}=\left\{m \in\{1 \ldots M\}: y_{p m t}=1\right\}$ e $U_{p t}=\left\{m \in\{1 \ldots M\}: y_{p m t}=0\right\}$ para todo produto $p$ e período $t$.

Considere agora $m^{\prime} \in S_{p t}$ e $m^{\prime \prime} \in U_{p t}$, então uma solução $y^{\prime}$ é vizinha de uma solução factível $y$ quando elas diferem em, no máximo, duas variáveis, sendo obrigatoriamente $y_{p m^{\prime} t}=$ 0 e com a possibilidade de $y_{p m^{\prime \prime} t}=1$, para algum produto $p$ ou período $t$. A Figura 3.3 apresenta exemplos de soluções vizinhas de uma determinada solução.

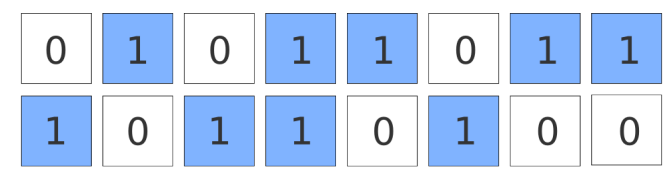

(a) Solução factível

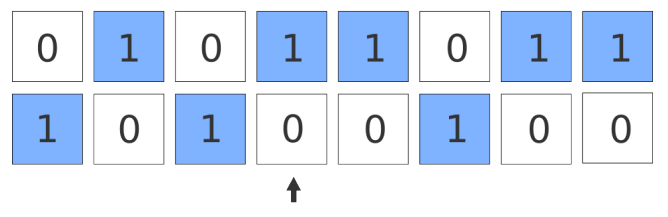

(b) Solução vizinha de (a) com uma única mudança nas preparações

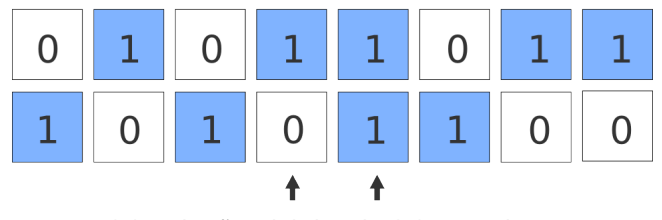

(c) Solução vizinha de (a) com duas mudanças nas preparações

Preparações de máquina para a produção ativas

Figura 3.3: Vizinhança de busca utilizada por Pedroso e Kubo (2005).

Diferentemente do usual, os autores aplicam a busca tabu até encontrar um mínimo local e somente o último movimento realizado no processo de descida é considerado tabu. O número de iterações que um movimento é considerado tabu pertence ao intervalo $[1, N \times M \times T]$ e é definido aleatoriamente. Em seguida, uma porcentagem das variáveis de preparação é escolhida também aleatoriamente para ser fixada. Sobre o restante das variáveis, é aplicado o método relax-and-fix obtendo, assim, uma nova solução inicial. A escolha aleatória de variáveis para serem fixadas permite obter diferentes soluções iniciais como ponto de reinicialização para a busca tabu. O processo é repetido até que o critério de parada seja satisfeito. A heurística apresentada pelos autores é resumida no Algoritmo 3. 


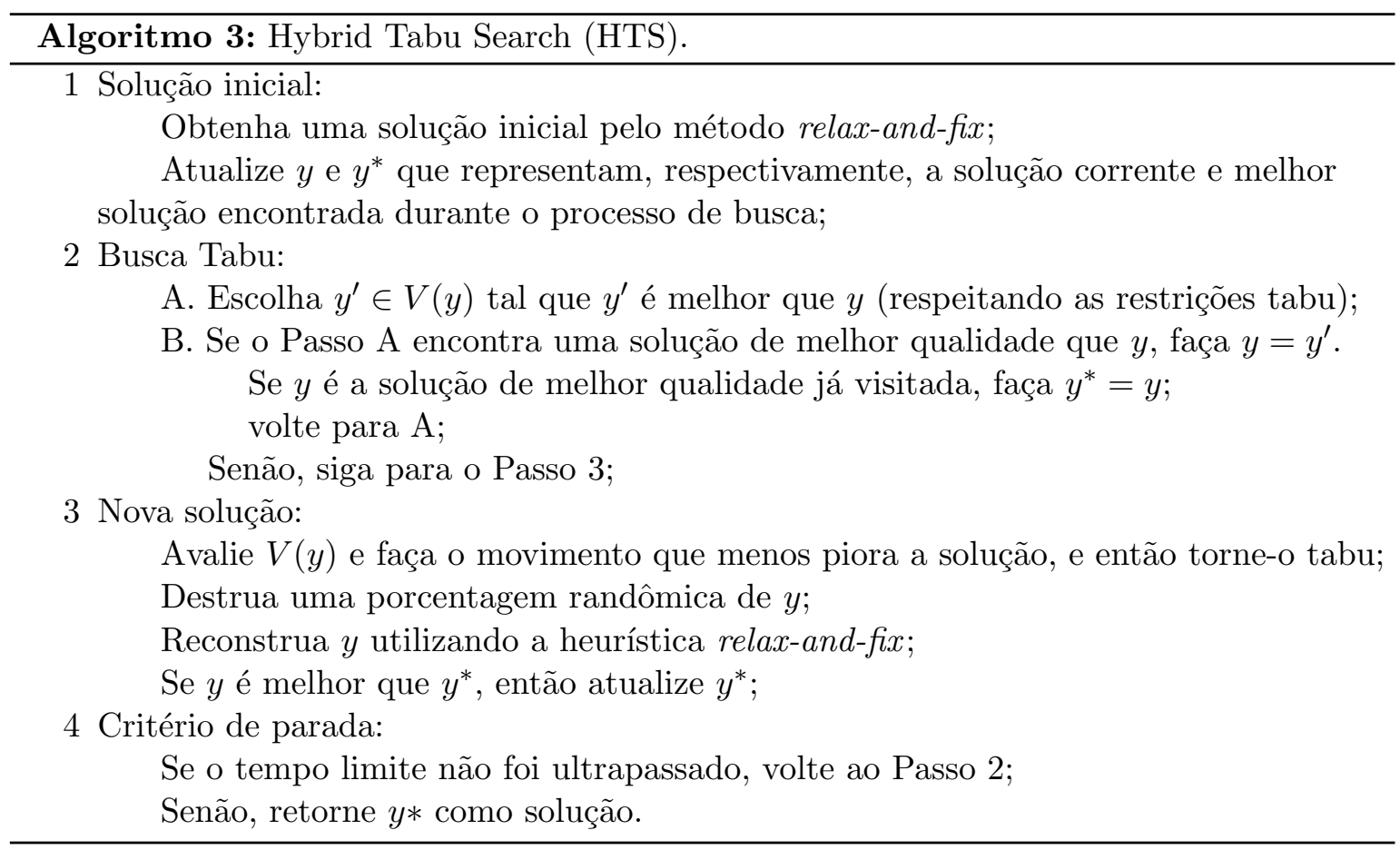

\subsection{Busca tabu proposta}

O primeiro método proposto consiste em uma busca tabu pura, ou seja, apenas com estruturas de memória de curto prazo. Nosso objetivo é desenvolver uma busca tabu determinística com base no trabalho de Pedroso e Kubo (2005) para mostrar que não é necessário utilizar a aleatoriedade para encontrar boas soluções.

A solução inicial da busca tabu é obtida por uma heurística relax-and-fix, similar à utilizada em Pedroso e Kubo (2005). O conjunto de variáveis tomadas como inteiras a cada iteração da heurística é dado por um produto, um período e todas as máquinas. Porém, definimos a ordem de escolha do conjunto que será inteiro a cada etapa da seguinte forma:

- Sequencial em relação aos períodos;

- Em cada período, são fixadas primeiramente as variáveis referentes aos produtos que possuem maior demanda.

Dessa forma, a heurística relax-and-fix utilizada no método proposto não contém fatores aleatórios. A partir da solução inicial, é possível iniciar a busca tabu.

Durante a busca, dizemos que uma solução $y^{\prime}$ é vizinha de uma solução factível $y$ quando ambas as soluções diferem exatamente em uma preparação de máquina. Quando um movimento é realizado, ele se torna tabu por um determinado número de iterações. Para decidirmos por quantas iterações um movimento permanecerá tabu, utilizamos uma lista de valores fixos. Cada vez que um movimento se torna tabu, ele permanece tabu por um número de iterações pré-estabelecido. Essa lista é percorrida sequencialmente e, quando chega ao fim, regressamos ao seu início, ou seja, percorremos a lista de forma cíclica. Dessa maneira, não 
exite fator aleatório na construção da lista tabu. A Figura 3.4 apresenta exemplos de soluções vizinhas de uma determinada solução.

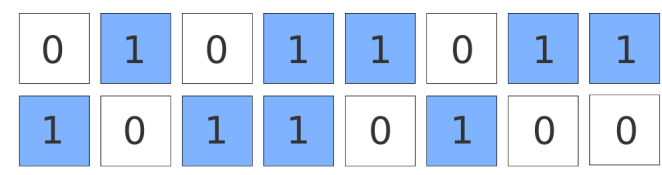

(a) Solução factível

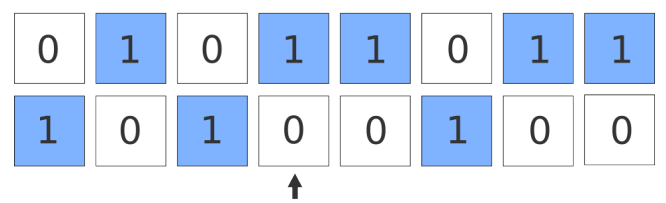

(b) Solução vizinha de (a) com uma preparação de máquina a menos.

Preparações de máquina para a produção ativas

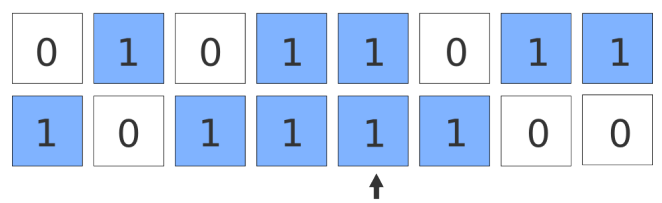

(c) Solução vizinha de (a) com uma preparação de máquina a mais.

Preparações de máquina para a produção inativas

Figura 3.4: Vizinhança de busca utilizada na busca tabu proposta.

Em contraste com as restrições tabu, utilizamos dois critérios de aspiração para que o método possa realizar movimentos considerados tabu. O primeiro é aplicado somente quando todos os movimentos são tabu. Nesse caso, verificamos qual movimento iria ficar por menos iterações como tabu, subtraímos o valor de toda a lista tabu e, então, tentamos novamente realizar um movimento. O segundo critério é utilizado quando um movimento que é tabu leva a melhor solução já encontrada pelo processo de busca. Nesse caso, ignoramos a restrição tabu e realizamos o movimento. O método proposto é resumido no Algoritmo 4 .

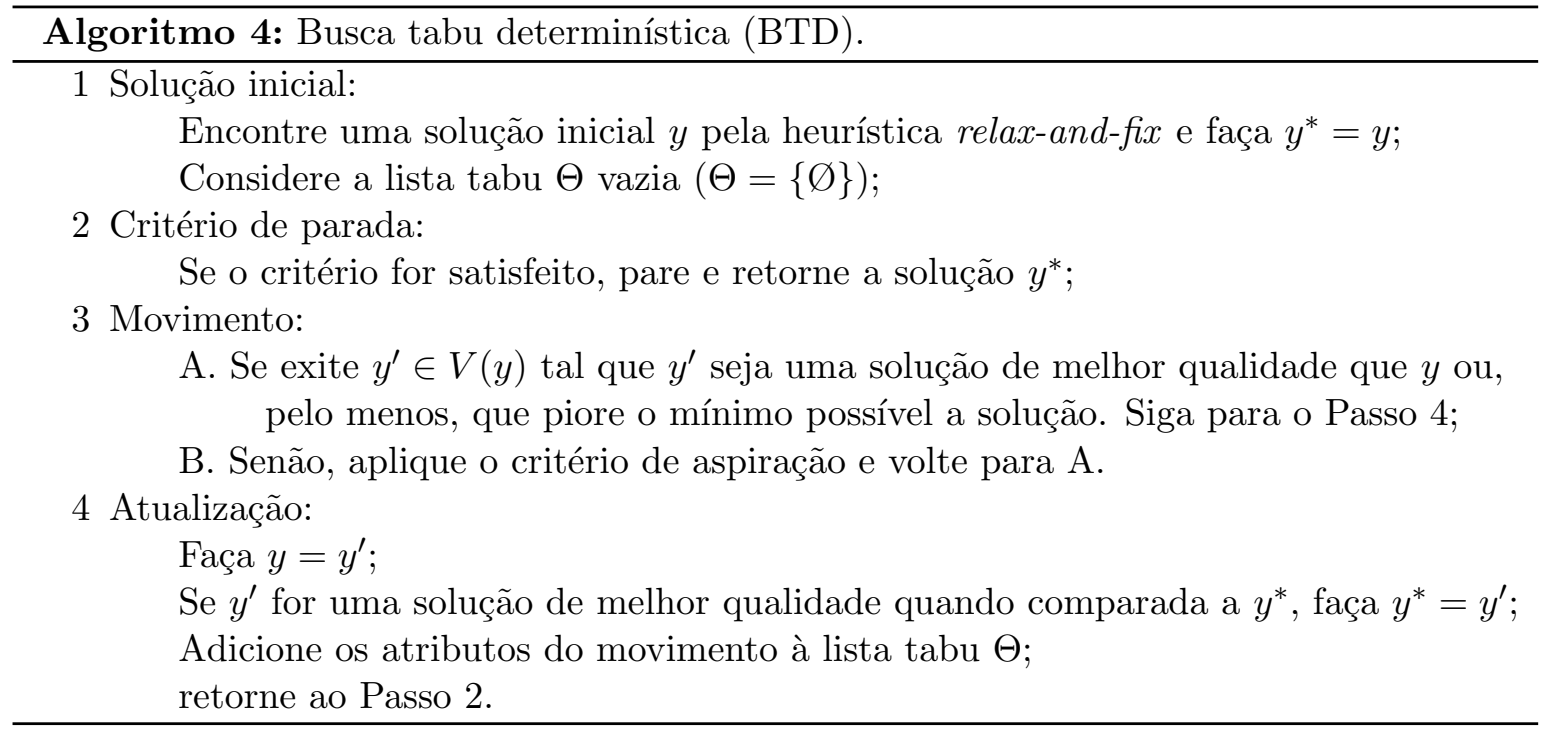

Como dito anteriormente, utilizar apenas memória de curto prazo tende a levar a busca a demandar um alto tempo computacional para encontrar soluções de boa qualidade. Logo, para melhorar a eficiência do método proposto, acrescentamos funções de memória de longo prazo tais como intensificação e diversificação. 


\subsubsection{Intensificação}

A estratégia da intensificação tem por objetivo retornar a busca para regiões consideradas promissoras, já visitadas anteriormente pelo processo de busca. Isso é feito analisando características das soluções encontradas durante um determinado período do processo de busca e, então, procurando por soluções que exibam características similares às dessas soluções.

A intensificação, aqui proposta, somente pode ser executada após um número mínimo de iterações, para que assim tenhamos informações sobre as regiões visitadas e possamos inferir qual é promissora. Satisfazendo essa restrição, o processo é executado toda vez que uma nova solução $y$ encontrada para o problema é um mínimo local e $y$ é melhor que $y^{*}$, ou seja, quando é encontrada uma solução de melhor qualidade para o problema. A estratégia consiste em fixar algumas variáveis, fazendo com que a busca tabu siga por uma região mais limitada, sendo assim mais ágil.

O critério para a fixação de variáveis baseia-se na frequência que as mesmas permaneceram ativas ou não nas soluções do problema. Seja $y$ uma de suas soluções, tal que $y$ é o melhor mínimo local visitado ao longo do processo de busca; então, uma variável é fixada como:

1) Ativa (em um) quando a variável em y é ativa e a frequência em que ela esteve ativa no decorrer da busca é maior que $70 \%$;

2) Não Ativa (em zero) quando a variável em y não é ativa e a frequência em que ela esteve ativa no decorrer da busca é menor que $30 \%$.

Caso nenhuma dessas condições seja satisfeita, a variável se mantém disponível para ser alterada pela busca local.

Testes computacionais iniciais mostraram que um bom número mínimo de iterações para o processo de intensificação poder ser realizado é de aproximadamente $80 \%$ do número de variáveis inteiras que o problema possui $(0,8 \times N \times M \times T)$. Quando ativo, o processo é executado por $0,2 \times N \times M \times T$ iterações.

\subsubsection{Diversificação}

O objetivo da diversificação é explorar novas regiões, ou seja, é buscar soluções que contrastem com as encontradas durante um determinado número de iterações do processo de busca. O processo é realizado de maneira inversa à intensificação, ou seja, é feita uma análise das características das soluções encontradas durante a busca e, então, procura-se por soluções que contrastem com essas características, gerando um novo ponto de partida para a busca.

A estratégia de diversificação adotada consiste em penalizar os movimentos da busca de acordo com a frequência que uma dada preparação de máquina ocorre. A penalização é feita somando ao custo de preparação de máquina à frequência com a qual a variável apareceu multiplicada por mil. Dessa forma, quanto mais frequente é uma preparação de máquina durante o processo, mais ela é penalizada. A diversificação ocorre por um número predeterminado de iterações, e, ao final do processo, o que se espera é obter uma solução que tenha pouca semelhança com as soluções visitadas durante a busca. 
Testes computacionais iniciais mostraram que um bom número de iterações para ativar o processo de diversificação é aproximadamente $60 \%$ do número de variáveis inteiras que o problema possui $(0,6 \times N \times M \times T)$. Quando ativa, a diversificação é executada por $0,2 \times N \times M \times T$ iterações.

\subsubsection{Busca tabu com memória de longo prazo}

O segundo método proposto consiste em adicionar a busca tabu às estratégias de intensificação e diversificação descritas. Nosso objetivo é acelerar o processo de convergência da heurística para soluções de boa qualidade. A nova heurística é resumida no Algoritmo 5 no qual a função $\bmod \{a, b\}$ retorna o resto da divisão inteira de $a$ por $b$.

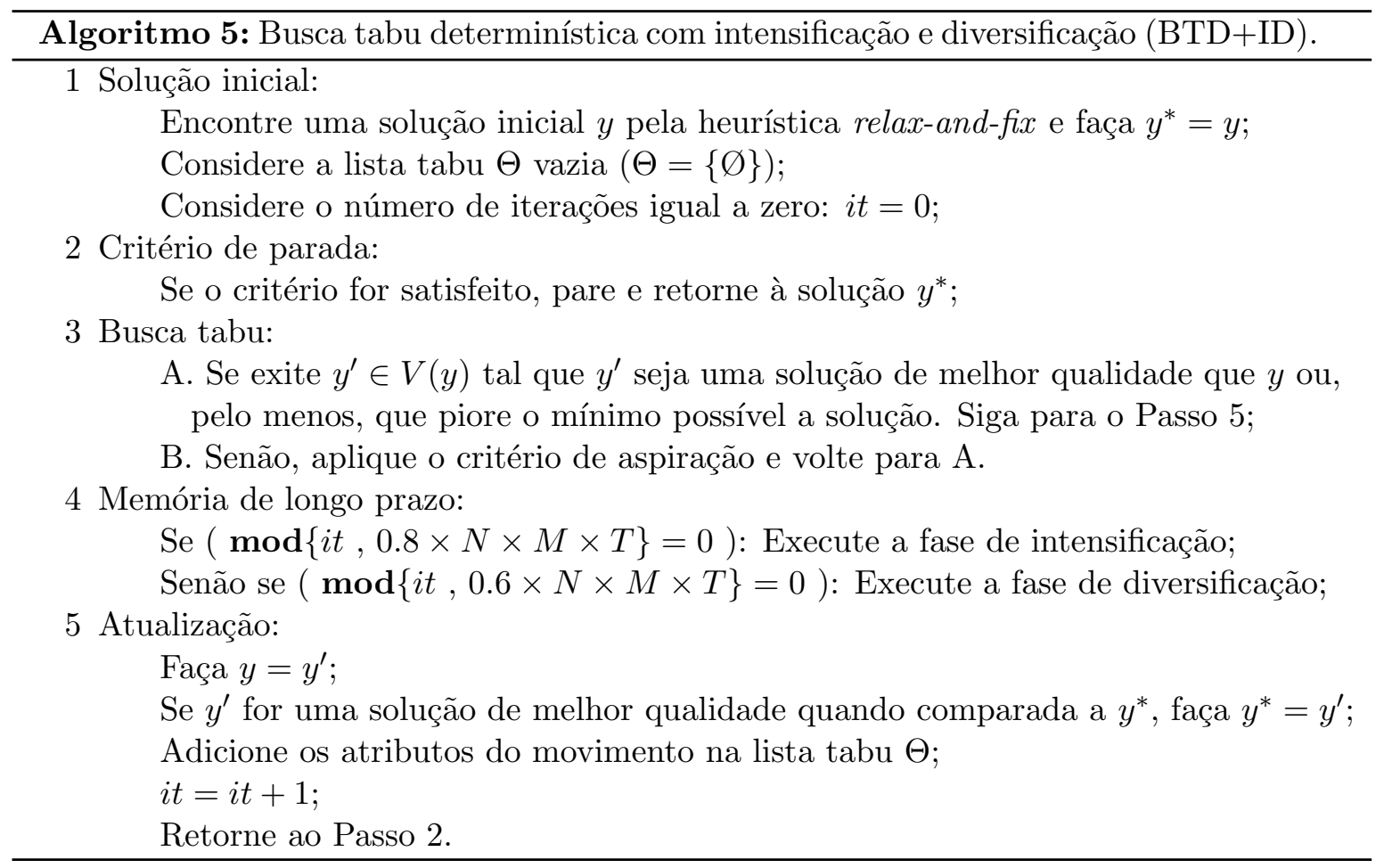

Em ambos os métodos propostos nesta seção, a heurística relax-and-fix é utilizada somente na inicialização do método. Assim, desde que uma solução inicial seja encontrada, o método pode ser aplicado sem exigir a possibilidade de entrega da demanda com atraso. Uma alternativa plausível para encontrar uma solução factível é utilizar a primeira solução encontrada pelo método branch-and-cut.

\subsection{Resultados}

Nesta seção, são apresentados os resultados computacionais realizados. Os testes foram realizados em duas etapas. Na primeira, os métodos foram avaliados considerando apenas uma máquina disponível; já na segunda, consideramos 4 e 6 máquinas. Na Subseção 3.4.1. detalhamos os testes efetuados na primeira etapa. Na Subseção 3.4.2, são apresentados os 
resultados computacionais da segunda etapa.

\subsubsection{Primeira etapa de testes (1 máquina)}

As instâncias utilizadas para avaliar as heurísticas estudadas foram propostas ou baseadas em Trigeiro et al. (1989). Para essas instâncias, não é permitido atender as demandas com atraso. Portanto, para considerar essa possibilidade foi adicionado o custo de atendimento da demanda com atraso, definido para cada um dos produtos como 1,5 vezes seu custo de estoque. Além disso, entre as instâncias propostas pelo autor, restringimos nosso foco à Classe G, a qual contém as instâncias consideradas mais difíceis (Belvaux e Wolsey, 2000). Deste conjunto de instâncias, descartamos as instâncias que contemplam a produção de apenas 6 produtos. Assim ficamos com as 20 instâncias de maior dimensão dessa classe que são igualmente distribuídas em quatro grupos:

- G51-G55: instâncias com 12 produtos e 15 períodos;

- G56-G60: instâncias com 24 produtos e 15 períodos;

- G66-G70: instâncias com 12 produtos e 30 períodos;

- G71-G75: instâncias com 24 produtos e 30 períodos.

Também utilizaremos as instâncias propostas por Muller et al. (2012). Com base nas instâncias G51-G60 e G66-G75 de Trigeiro et al. (1989), os autores propuseram instâncias maiores. Primeiramente, são descartados os custos de preparação de máquina e, em seguida, todas as demandas nulas são aumentadas para dois. A dimensão das instâncias com 15 períodos é dobrada e triplicada; para tanto, os dados dos 15 primeiros períodos são repetidos uma ou duas vezes. O mesmo é feito com as instâncias com 30 períodos. Logo, temos instâncias com 15, 30 e 45 períodos e instâncias com 30, 60 e 90 períodos, que foram divididas nos seguintes grupos:

- G51 $1^{30}-\mathrm{G} 55^{30}$ : instâncias com 12 produtos e 30 períodos;

- $\mathrm{G} 56^{30}-\mathrm{G} 60^{30}$ : instâncias com 24 produtos e 30 períodos;

- G51 ${ }^{45}-\mathrm{G} 55^{45}$ : instâncias com 12 produtos e 45 períodos;

- $\mathrm{G} 56^{45}$-G60 ${ }^{45}$ : instâncias com 24 produtos e 45 períodos;

- $\mathrm{G} 66^{60}-\mathrm{G} 70^{60}$ : instâncias com 12 produtos e 60 períodos;

- G71 $71_{-}^{60} 75^{60}$ : instâncias com 24 produtos e 60 períodos;

- $\mathrm{G} 66^{90}-\mathrm{G} 70^{90}$ : instâncias com 12 produtos e 90 períodos;

- G71 ${ }^{90}-\mathrm{G} 75^{90}$ : instâncias com 24 produtos e 90 períodos.

A partir dessas 40 instâncias, os autores criam mais 40 em que o custo de estoque é homogêneo (igual a 1). As instâncias são nomeadas de forma similar às anteriores, acrescentando apenas o prefixo $\mathrm{H}$ ao seu nome. 
Para realizar os testes computacionais, as heurísticas apresentadas neste capítulo foram codificadas em linguagem $\mathrm{C} / \mathrm{C}++$ e os testes foram conduzidos num computador com processador Intel Core 2 Quad $3.00 \mathrm{GHz}$ com $4 \mathrm{~Gb}$ de memória e sistema operacional Ubuntu 12.04 (64 bits). O tempo limite de cinco minuto: $\bigsqcup^{1}$ foi imposto para resolução dos problemas. Para cada uma das instâncias, foi calculado o desvio percentual entre a solução obtida pelas heurísticas e o limitante inferior da solução fornecido pelo software CPLEX 12.1. Este desvio é calculado da seguinte maneira:

$$
\text { Desvio }=\frac{\mid(\text { Solução Heurística })-(\text { Limitante CPLEX }) \mid}{(\text { Limitante CPLEX })} \times 100 .
$$

De cada conjunto de instâncias, agrupamos as que possuíam o mesmo número de períodos e produtos e apresentamos somente a média dos desvios. Como a heurística proposta por Pedroso e Kubo (2005) (HTS) depende em grande parte de fatores aleatórios, cada uma das instâncias foi executada cinco vezes e, a partir dos resultados, foram selecionadas as médias dos desvios mínimos, médios e máximos por conjunto de instâncias.

As Tabelas 3.1 e 3.2 apresentam os desvios obtidos para cada um dos métodos apresentados para instâncias extraídas de Trigeiro et al. (1989) e Muller et al. (2012), respectivamente. Em todas as tabelas, a coluna CPLEX mostra os desvios obtidos pelo software CPLEX em 5 minutos de execução. As colunas HTS apresentam os desvios obtidos pelo método de Pedroso e Kubo (2005) no melhor caso, caso médio e pior caso. As colunas BTD e BTD+ID contêm os desvios obtidos pela busca tabu determinística, sendo a primeira apenas com estruturas de memória de curto prazo.

Tabela 3.1: Resultados para instâncias de Trigeiro et al. (1989) adaptadas.

\begin{tabular}{l|cccccc}
\hline & \multirow{2}{*}{ CPLEX } & \multicolumn{3}{|c}{ HTS } & \multirow{2}{*}{ BTD } & \multirow{2}{*}{ BTD+ID } \\
\cline { 3 - 6 } & & Mínimo & Média & Máximo & & \\
\hline G51 - G55 & $0.0 \%$ & $3.0 \%$ & $3.4 \%$ & $3.7 \%$ & $2.0 \%$ & $1.1 \%$ \\
\hline G56 - G60 & $0.0 \%$ & $3.4 \%$ & $3.9 \%$ & $4.3 \%$ & $2.5 \%$ & $2.1 \%$ \\
\hline G66 - G70 & $0.1 \%$ & $4.4 \%$ & $4.8 \%$ & $5.2 \%$ & $2.6 \%$ & $1.9 \%$ \\
\hline G71 - G75 & $0.1 \%$ & $5.1 \%$ & $5.5 \%$ & $5.9 \%$ & $2.7 \%$ & $2.7 \%$ \\
\hline Média & $\mathbf{0 . 0 \%}$ & $\mathbf{4 . 1 \%}$ & $\mathbf{4 . 4 \%}$ & $\mathbf{4 . 8 \%}$ & $\mathbf{2 . 4 \%}$ & $\mathbf{1 . 9 \%}$ \\
\hline
\end{tabular}

Analisando os resultados apresentados, observamos que o software CPLEX 12.1 obtém as melhores soluções para todas as instâncias. Para todas as heurísticas, a sensibilidade dos resultados em relação ao número de períodos do horizonte de planejamento foi menor para o conjunto de instâncias homogêneas. Focando a análise na heurística HTS de Pedroso e Kubo (2005), podemos verificar que a variabilidade da qualidade da solução é bastante alta para instâncias grandes, chegando a diferenças de até $79 \%$ entre os desvios máximo e mínimo $\left(\mathrm{G} 71^{90}-\mathrm{G} 75^{90}\right)$. Isso se justifica devido às poucas iterações realizadas até atingir o tempo limite da heurística. Para as instâncias da Tabela 3.1, as diferenças estão próximas a 1\%,

\footnotetext{
${ }^{1} \mathrm{O}$ tempo de 5 minutos foi adotado, pois os resultados serão comparados com os apresentados em Muller et al. (2012) que utilizou esse tempo computacional em uma máquina similar à nossa, segundo a análise da Standard Performance Evaluation Corporation (www.spec.org/).
} 
Tabela 3.2: Resultados para instâncias heterogêneas de Muller et al. (2012) adaptadas.

\begin{tabular}{|c|c|c|c|c|c|c|}
\hline & \multirow{2}{*}{ CPLEX } & \multicolumn{3}{|c|}{ HTS } & \multirow{2}{*}{ BTD } & \multirow{2}{*}{$\mathrm{BTD}+\mathrm{ID}$} \\
\hline & & Mínimo & Média & Máximo & & \\
\hline $\mathrm{G} 51^{30}-\mathrm{G} 55^{30}$ & $2.2 \%$ & $19.5 \%$ & $25.2 \%$ & $31.3 \%$ & $15.9 \%$ & $15.9 \%$ \\
\hline $\mathrm{G} 56^{30}-\mathrm{G} 60^{30}$ & $2.1 \%$ & $57.4 \%$ & $71.0 \%$ & $87.0 \%$ & $57.5 \%$ & $57.3 \%$ \\
\hline $\mathrm{G} 66^{60}-\mathrm{G} 70^{60}$ & $9.1 \%$ & $96.8 \%$ & $116.2 \%$ & $147.4 \%$ & $75.7 \%$ & $74.1 \%$ \\
\hline $\mathrm{G} 71^{60}-\mathrm{G} 75^{60}$ & $9.9 \%$ & $98.4 \%$ & $124.9 \%$ & $147.0 \%$ & $108.6 \%$ & $108.3 \%$ \\
\hline G5 $1^{45}-G 55^{45}$ & $4.2 \%$ & $29.7 \%$ & $46.1 \%$ & $70.0 \%$ & $27.0 \%$ & $26.0 \%$ \\
\hline $\mathrm{G} 56^{45}-\mathrm{G} 60^{45}$ & $3.0 \%$ & $76.5 \%$ & $88.2 \%$ & $103.3 \%$ & $66.4 \%$ & $65.7 \%$ \\
\hline $\mathrm{G} 66^{90}-\mathrm{G} 70^{90}$ & $10.3 \%$ & $100.0 \%$ & $115.8 \%$ & $133.5 \%$ & $56.0 \%$ & $55.1 \%$ \\
\hline Média & $10.4 \%$ & $68.3 \%$ & $77.9 \%$ & $88.0 \%$ & $54.3 \%$ & $54.2 \%$ \\
\hline
\end{tabular}

Tabela 3.3: Resultados para instâncias homogêneas de Muller et al. (2012) adaptadas.

\begin{tabular}{|c|c|c|c|c|c|c|}
\hline & \multirow{2}{*}{ CPLEX } & \multicolumn{3}{|c|}{ HTS } & \multirow{2}{*}{ BTD } & \multirow{2}{*}{$\mathrm{BTD}+\mathrm{ID}$} \\
\hline & & Mínimo & Média & Máximo & & \\
\hline $\mathrm{HG} 51^{30}-\mathrm{HG} 55^{30}$ & $6.7 \%$ & $32.7 \%$ & $39.1 \%$ & $47.1 \%$ & $38.7 \%$ & $38.8 \%$ \\
\hline HG56 $6^{30}-\mathrm{HG} 60^{30}$ & $3.9 \%$ & $57.7 \%$ & $66.7 \%$ & $73.4 \%$ & $38.1 \%$ & $38.6 \%$ \\
\hline $\mathrm{HG} 66^{60}-\mathrm{HG} 70^{60}$ & $10.7 \%$ & $73.1 \%$ & $82.3 \%$ & $92.7 \%$ & $46.3 \%$ & $46.3 \%$ \\
\hline $\mathrm{HG}^{2} 1^{60}-\mathrm{HG} 75^{60}$ & $18.7 \%$ & $89.6 \%$ & $104.8 \%$ & $120.9 \%$ & $71.5 \%$ & $71.6 \%$ \\
\hline HG5 $1^{45}-\mathrm{HG} 55^{45}$ & $8.8 \%$ & $42.2 \%$ & $52.1 \%$ & $62.2 \%$ & $42.2 \%$ & $42.6 \%$ \\
\hline HG56 $6^{45}-$ HG60 ${ }^{45}$ & $4.6 \%$ & $69.7 \%$ & $75.1 \%$ & $81.2 \%$ & $49.0 \%$ & $48.9 \%$ \\
\hline $\mathrm{HG} 66^{90}-\mathrm{HG} 70^{90}$ & $12.2 \%$ & $84.0 \%$ & $93.6 \%$ & $103.3 \%$ & $59.1 \%$ & $58.1 \%$ \\
\hline $\mathrm{HG} 71^{90}-\mathrm{HG} 75^{90}$ & $17.5 \%$ & $97.4 \%$ & $109.8 \%$ & $123.6 \%$ & $89.1 \%$ & $88.9 \%$ \\
\hline Média & $6.6 \%$ & $72.3 \%$ & $90.9 \%$ & $112.4 \%$ & $66.1 \%$ & $65.4 \%$ \\
\hline
\end{tabular}


que, apesar de ser uma porcentagem baixa, é de alta magnitude quando comparado ao valor dos desvios obtidos pelo método para essas instâncias. A variabilidade pode ser um reflexo negativo dos fatores aleatórios presentes na heurística.

Comparando as heurísticas BTD e BTD+ID, podemos notar que existe um ganho significativo na qualidade da solução quando é usada a intensificação e diversificação, principalmente para instâncias de pequeno porte como as apresentadas na Tabela 3.1. Quando analisamos instâncias de grande porte, como as apresentadas nas Tabelas 3.2 e 3.3 , o desempenho de ambas as heurísticas foi muito similar. Isso se deve ao fato de que, para essas instâncias, a heurística BTD+ID não consegue atingir o número de iterações necessárias para ativar os processos de diversificação e intensificação e assim elas obtêm resultados muito similares aos da heurística BTD.

Finalmente, note que as heurísticas determinísticas obtêm desvios de otimalidade menores em quase todos os casos quando comparadas ao melhor caso da heurística HTS e sempre são melhores ou iguais quando comparados ao caso médio. A análise evidência que o uso de fatores aleatórios não é necessário para a obtenção de bons resultados e, ainda, sua utilização pode resultar em instabilidade quanto à qualidade da solução obtida.

\subsubsection{Segunda etapa de testes (máquinas paralelas)}

Com a finalidade de averiguar o desempenho dos métodos para problemas com máquinas paralelas, utilizamos parte das instâncias geradas em Toledo e Armentano (2006). No artigo, os autores propõem instâncias com 6, 12 e 18 períodos; 6, 12, 25 e 50 produtos e 2, 4 e 6 máquinas para o problema, dando origem a 36 tipos de instância. Para cada tipo de instância, 10 exemplares são gerados. Neste trabalho, utilizamos apenas as instâncias que mais se aproximam das apresentadas em Trigeiro et al. (1989), as quais têm capacidade de produção normal e custos e tempos de preparação para a produção baixos. Ainda desse conjunto, selecionamos instâncias com 6, 12 e 18 períodos, 4 e 6 máquinas e 12 e 50 produtos, originando 18 tipos de instância para as quais cinco exemplares são gerados, totalizando 60 novas instâncias. Classificamos as instâncias como:

- $\mathrm{T} 1^{m, t}-\mathrm{T} 5^{m, t}:$ instâncias com 12 produtos, $m$ máquinas e $t$ períodos;

- $\mathrm{T} 6^{m, t}-\mathrm{T} 10^{m, t}$ : instâncias com 50 produtos, $m$ máquinas e $t$ períodos.

A Tabela 3.4 apresenta os desvios obtidos pelos métodos ao resolver essas instâncias. Ao analisar os resultados, podemos notar que os desvios obtidos por todos os métodos são de baixa magnitude. Focando a análise para a heurística HTS, as diferenças entre os desvios entre o melhor e o pior caso dados são de no máximo $0.5 \%\left(\mathrm{~T} 1^{6,18}-\mathrm{T} 5^{6,18}\right)$ e no mínimo $0.1 \%\left(\mathrm{~T} 1^{4,6}-\mathrm{T} 5^{4,6}\right)$. Estes valores, apesar de serem baixos, são de grande magnitude quando se comparam ao valor dos desvios.

Novamente a heurística BTD+ID, quando comparada à heurística BTD, apresenta resultados melhores, chegando a reduzir os desvios pela metade $\left(\mathrm{T} 6^{4,18}-\mathrm{T} 10^{4,18}\right)$. Ainda, quanto ao desempenho do caso médio da heurística HTS e da heurística BTD+ID, podemos verificar que os resultados obtidos pela segunda são sempre de qualidade melhor ou igual aos da heurística aleatória, chegando a ter um desvio $0.6 \%$ mais baixo $\left(\mathrm{T} 6^{4,18}-\mathrm{T} 10^{4,18}\right)$. 
Tabela 3.4: Resultados obtidos a partir de instâncias de Toledo e Armentano (2006) adaptadas.

\begin{tabular}{l|cccccc}
\hline & \multirow{2}{*}{ CPLEX } & \multicolumn{3}{c}{ HTS } & \multirow{2}{*}{ BTD } & \multirow{2}{*}{ BTD+ID } \\
\cline { 2 - 5 } & & Mínimo & Média & Máximo & & \\
\hline $\mathrm{T} 1^{4,6}-\mathrm{T} 5^{4,6}$ & $0.0 \%$ & $0.3 \%$ & $0.4 \%$ & $0.4 \%$ & $0.5 \%$ & $0.2 \%$ \\
\hline $\mathrm{T} 1^{4,12}-\mathrm{T} 5^{4,12}$ & $0.1 \%$ & $0.7 \%$ & $0.9 \%$ & $1.1 \%$ & $0.8 \%$ & $0.7 \%$ \\
\hline $\mathrm{T} 1^{4,18}-\mathrm{T} 5^{4,18}$ & $0.2 \%$ & $1.1 \%$ & $1.3 \%$ & $1.6 \%$ & $1.2 \%$ & $0.8 \%$ \\
\hline $\mathrm{T} 6^{4,6}-\mathrm{T} 10^{4,6}$ & $0.0 \%$ & $0.4 \%$ & $0.5 \%$ & $0.6 \%$ & $0.5 \%$ & $0.3 \%$ \\
\hline $\mathrm{T} 6^{4,12}-\mathrm{T} 10^{4,12}$ & $0.0 \%$ & $0.8 \%$ & $0.9 \%$ & $1.0 \%$ & $0.8 \%$ & $0.8 \%$ \\
\hline $\mathrm{T} 6^{4,18}-\mathrm{T} 10^{4,18}$ & $0.0 \%$ & $1.1 \%$ & $1.2 \%$ & $1.3 \%$ & $1.2 \%$ & $0.6 \%$ \\
\hline $\mathrm{T} 1^{6,6}-\mathrm{T} 5^{6,6}$ & $0.0 \%$ & $0.2 \%$ & $0.3 \%$ & $0.3 \%$ & $0.5 \%$ & $0.3 \%$ \\
\hline $\mathrm{T} 1^{6,12}-\mathrm{T} 5^{6,12}$ & $0.1 \%$ & $0.5 \%$ & $0.8 \%$ & $1.0 \%$ & $1.0 \%$ & $0.8 \%$ \\
\hline $\mathrm{T} 1^{6,18}-\mathrm{T} 5^{6,18}$ & $0.2 \%$ & $0.7 \%$ & $0.9 \%$ & $1.2 \%$ & $0.7 \%$ & $0.6 \%$ \\
\hline $\mathrm{T} 6^{6,6}-\mathrm{T} 10^{4,6}$ & $0.0 \%$ & $0.4 \%$ & $0.5 \%$ & $0.6 \%$ & $0.5 \%$ & $0.5 \%$ \\
\hline $\mathrm{T} 6^{6,12}-\mathrm{T} 10^{4,12}$ & $0.1 \%$ & $0.8 \%$ & $0.9 \%$ & $1.0 \%$ & $0.9 \%$ & $0.8 \%$ \\
\hline $\mathrm{T} 6^{6,18}-\mathrm{T} 10^{4,18}$ & $0.1 \%$ & $1.0 \%$ & $1.1 \%$ & $1.2 \%$ & $1.3 \%$ & $1.1 \%$ \\
\hline Média & $\mathbf{0 . 1 \%}$ & $\mathbf{0 . 7 \%}$ & $\mathbf{0 . 8 \%}$ & $\mathbf{0 . 9 \%}$ & $\mathbf{0 . 8 \%}$ & $\mathbf{0 . 6 \%}$ \\
\hline
\end{tabular}

Também é possível notar que o número de produtos a serem produzidos e máquinas não influencia de forma significativa os desvios de otimalidade. Por outro lado, com o crescimento do número de períodos, os desvios aumentam significativamente, o que mostra que a dificuldade na resolução do problema a partir desse tipo de heurística está fortemente atrelada ao número de períodos do horizonte de planejamento.

\subsection{Conclusões}

Não foram utilizados, a critério de comparação, nesta etapa do trabalho, a heurística lagrangeana proposta em Toledo e Armentano (2006) e o método heurístico proposto em Muller et al. (2012), pois contemplam o planejamento da produção sem a possibilidade de atrasos nas entregas dos produtos, e o método de Pedroso e Kubo (2005) não pode ser aplicado sem essa característica.

Neste capítulo, concluímos que a aleatoriedade, como o esperado, não é uma ferramenta necessária para a obtenção de bons resultados pela busca tabu. Isso foi realizado desenvolvendo heurísticas determinísticas similares à heurística aleatória apresentada em Pedroso e Kubo (2005) e, então, realizando testes computacionais e confrontando-os, podendo ver, com clareza, que a heurística aleatória apresenta resultado com desvios maiores que as heurísticas determinísticas. Ainda, foi possível verificar que o uso da aleatoriedade pode trazer insegurança quanto à qualidade da solução obtida pela heurística.

Também foi possível verificar que os processos de intensificação e diversificação, quando são incorporados à busca tabu, proporcionam uma grande melhoria na qualidade da solução, reduzindo significativamente os desvios de otimalidade, podendo sua utilização ser um fator importante para a obtenção de uma solução de boa qualidade. 
As heurísticas apresentadas, neste capítulo, têm bom desempenho na busca por soluções para problemas pequenos, nos quais o software CPLEX 12.1 não tem muitas dificuldades em encontrar soluções com baixos desvios ou até mesmo ótimas em tempo computacional viável. Assim, não pode ser justificado o uso dessas heurísticas na resolução dos problemas.

No próximo capítulo, dedicamo-nos a desenvolver uma busca tabu com uma região de busca mais abrangente, que possa ser aplicada a problemas em que atrasos nas entregas não são admitidos. 


\section{Capítulo 4}

\section{Método Híbrido}

Neste capítulo, apresentaremos um método híbrido para a resolução do problema de dimensionamento de lotes. Com base no Capítulo3, sabemos que o uso de aleatoriedade não é necessário para obter bons resultados para heurísticas do tipo busca tabu. Dessa forma, a heurística aqui apresentada foi construída de maneira completamente determinística.

O método proposto se baseia no trabalho de Woodcock e Wilson (2010). Nosso objetivo é obter uma busca tabu com uma vizinhança de busca similar à adotada pelos autores e estratégias de intensificação e diversificação de solução específicas para o problema de dimensionamento de lotes estudado.

No texto que segue, como nosso método está baseado no trabalho de Woodcock e Wilson (2010), resumimos na Seção 4.1 a proposta dos autores. Na Seção 4.2. propomos um método híbrido (matheurística) para o problema de dimensionamento de lotes estudado. Na Seção 4.3. reportamos os testes computacionais realizados para avaliar o método proposto. Por fim, na Seção 4.4, apresentamos algumas considerações finais.

\subsection{Proposta de Woodcock e Wilson (2010)}

Woodcock e Wilson (2010) propuseram uma matheurística para resolver o problema de designação generalizada. Esse método combina busca tabu e branch-and-bound.

O problema de designação generalizada consiste em minimizar os custos (ou maximizar os lucros) ao atribuir $n$ tarefas a $m$ agentes, de forma que: a) cada tarefa seja associada somente a um agente; e b) a quantidade de tarefas atribuídas a um agente não ultrapasse sua capacidade de realizá-las. A modelagem do problema utilizada pelos autores é dada por:

$$
\begin{array}{rll}
\operatorname{minimizar} & \sum_{i=1}^{m} \sum_{j=1}^{n} \delta_{i j} w_{i j}, & \\
\text { sujeito a: } & \sum_{j=1}^{n} \alpha_{i j} w_{i j} \leq \Theta_{i}, & \forall i \in I \\
& \sum_{i=1}^{m} w_{i j}=1, \quad \forall j \in J \\
& w_{i j} \in\{0,1\} . & \forall i \in I, j \in J
\end{array}
$$

em que: 
- $I=\{1, \ldots, n\}:$ Conjunto de agentes;

- $J=\{1, \ldots, m\}:$ Conjunto de tarefas;

- $\delta_{i j}$ : Custo de atribuir ao agente $i$ a tarefa $j$;

- $\alpha_{i j}$ : Quantidade de recursos que o agente $i$ gasta para realizar a tarefa $j$;

- $\Theta_{i}$ : Quantidade de recurso que o agente $i$ possui para a realização das tarefas;

- $w_{i j}$ : Assume o valor 1 se o agente $i$ realiza a tarefa $j$ e 0 caso contrário.

No modelo (4.1) - 4.4 , a função objetivo (4.1) visa minimizar a soma dos custos para realização das tarefas. As restrições $(4.2$ garantem que a quantidade de recursos que cada agente possui para a realização das tarefas não é ultrapassada. As equações (4.3) asseguram que cada tarefa seja realizada por um único agente. As restrições (4.4 definem o domínio das variáveis de decisão.

Segundo Fisher et al. (1986) e Sahni e Gonzalez (1976), o problema de designação generalizada é um problema de otimização combinatória classificado como NP-difícil. Devido à dificuldade de encontrar uma solução ótima para o problema, diversos trabalhos da literatura propõem métodos heurísticos para sua resolução. Como, por exemplo, Woodcock e Wilson (2010) que propõem uma matheurística que combina busca tabu e branch-and-bound para resolvê-lo.

Similar ao proposto pelos autores, uma solução inicial para o método é obtida utilizando o algoritmo branch-and-cut para resolver o problema até que uma primeira solução factível seja encontrada. Note que, se o branch-and-cut terminar sem encontrar uma solução factível, o problema é infactível.

Uma vez obtida uma solução inicial, a matheurística segue tendo a busca tabu como mestre, a qual pode ser dividida em três partes principais: a busca com memória de curto prazo, intensificação e diversificação. Inicialmente, é utilizada a busca com memória de curto prazo, seguida da fase de intensificação. Se na fase de intensificação for encontrada uma solução de qualidade para o problema, o processo volta para a fase de busca com memória de curto prazo; caso contrário, o processo segue para a fase de diversificação que gera uma nova solução. Esta solução é utilizada como ponto de partida para a busca tabu com memória de curto prazo. O critério de parada para o algoritmo é o tempo de execução.

A interação entre a busca tabu com memória de curto prazo e o branch-and-cut ocorre na estrutura de vizinhança considerada. Dada uma solução factível $\bar{w}$ para 4.1)-4.4, para definir a vizinhança dessa solução, os autores constroem o conjunto $D=\left\{(i, j): \bar{w}_{i j}=1\right\}$, ou seja, um conjunto com todas as variáveis binárias que representam as designações ativas (iguais a um). A partir desse conjunto, é imposta a restrição:

$$
\sum_{(i, j) \in D} w_{i j} \leq|D|-1 .
$$


A restrição 4.5 garante que ao menos uma das designações da solução $\bar{w}$ não ocorrerá. Em seguida, é realizada, como chamada pelos autores, a operação de redução de vizinhança, que consiste em encontrar a solução ótima do seguinte problema linear:

$$
\begin{array}{rc}
\text { minimizar } & \sum_{i=1}^{m} \sum_{j=1}^{n} \delta_{i j} w_{i j}, \\
\text { sujeito a: } & 4.2-4.3, \\
& \sum_{(i, j) \in D} w_{i j} \leq|D|-1, \quad \\
& 0 \leq w_{i j} \leq 1 . \quad \forall i \in I, j \in J
\end{array}
$$

A partir da solução ótima desse problema $\left(\bar{w}_{r}\right)$, são fixadas, no problema original, como ativas as designações que pertencem ao conjunto $D$ e são totalmente ativas (assumem o valor um) em $\bar{w}_{r}$. Então, o problema inteiro resultante é resolvido pelo método branch-and-cut. A nova solução obtida é considerada vizinha da solução anterior. Esse processo define a melhor solução vizinha de $\bar{w}$.

A fase de intensificação é realizada fixando as designações que são ativas na melhor solução encontrada e foram ativas com mais frequência durante o processo de busca. O restante das variáveis são mantidas livres. Além disso, os autores impõem, em forma de restrição, que a nova solução seja de melhor qualidade que a melhor solução obtida durante o processo de busca. Isso é feito com o intuito de reduzir o tempo necessário para concluir a intensificação. Após a intensificação, dois caminhos podem ser tomados no processo de busca. Se uma solução factível for encontrada, o processo retorna à busca com memória de curto prazo, senão a busca segue para a fase de diversificação.

No processo de diversificação, os autores exigem que as designações que foram ativas com baixa frequência durante o processo de busca sejam ativas. A qualidade da solução encontrada é usualmente ruim, porém leva a busca para uma região ainda não explorada. $\mathrm{O}$ método proposto pelos autores é resumido no Algoritmo 6, no qual, $w^{*}$ e $z^{*}$ correspondem, respectivamente, à melhor solução encontrada e a seu valor. O número de iterações da memória de curto prazo é dado por $\Omega$, cujo valor é tomado com base na razão $n / m$ (número de tarefas/número de agentes).

Testes computacionais realizados pelos autores mostraram que esse método é competitivo com outras heurísticas da literatura.

\subsection{Método híbrido proposto}

O método híbrido proposto foi desenvolvido com base no trabalho de Woodcock e Wilson (2010) que consiste em realizar uma busca tabu utilizando uma estrutura de vizinhança mais abrangente que a usual. Chamaremos esse método de BTVA (busca tabu com vizinhança abrangente). A qualidade da vizinhança de busca depende fortemente de uma relaxação linear que se aproxime da envoltória convexa do problema, ou seja, que a solução do problema linearmente relaxado possua uma boa parte de seus valores inteiros. Portanto, utilizaremos a 


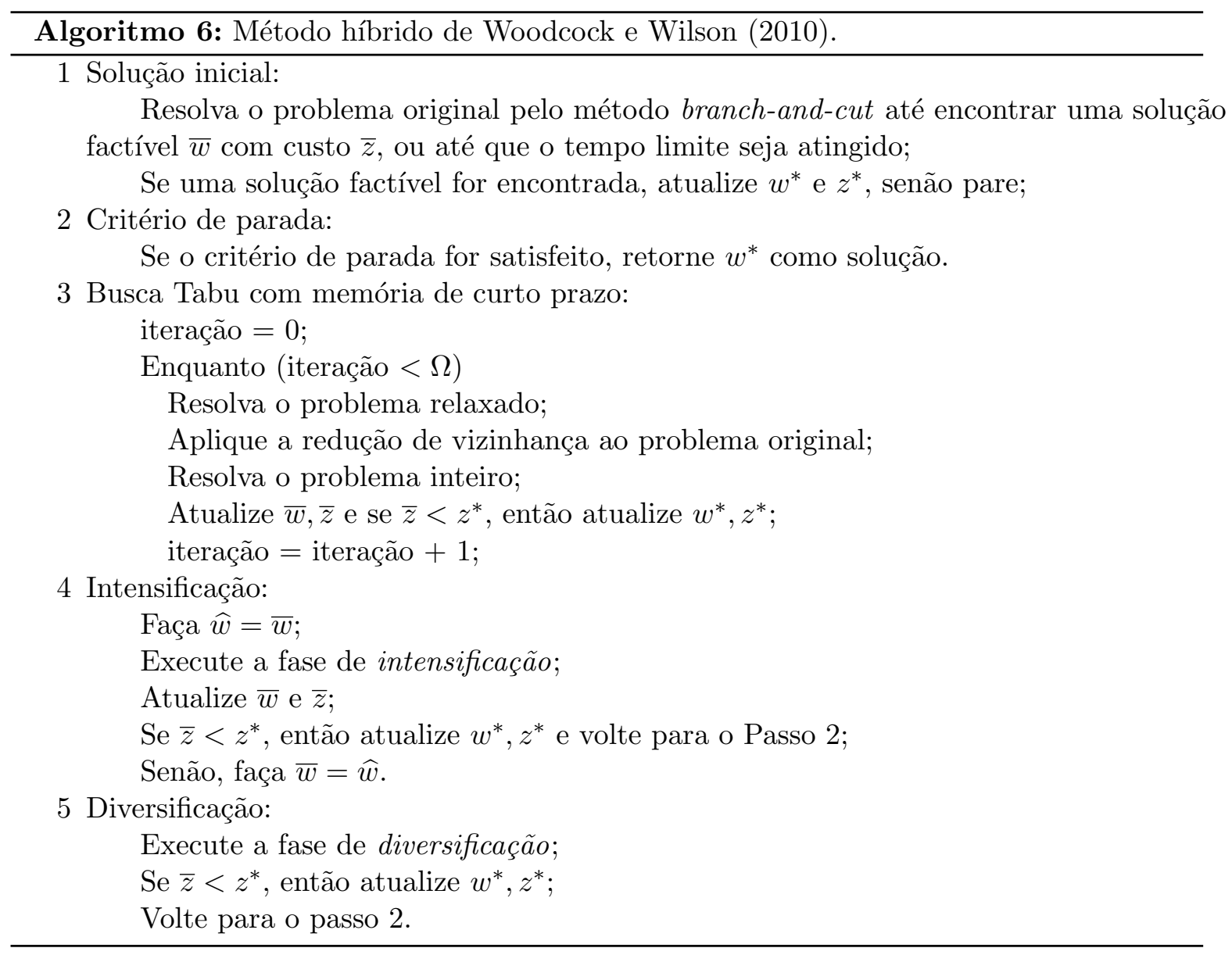

modelagem de Krarup e Bilde (1977) apresentada na Sessão 2.2.2 uma vez que sua relaxação linear possui as características desejadas.

O método proposto pode ser dividido em quatro partes principais, que são: a) inicialização; b) busca tabu com memória de curto prazo; c) intensificação; e d) diversificação. No decorrer desta seção, utilizaremos a seguinte notação para armazenar os valores das variáveis inteiras, ou seja, das preparações para produção:

- $y^{r}$ : Preparações para produção realizadas na solução do problema linearmente relaxado;

- $y^{*}$ : Preparações para produção realizadas na melhor solução factível encontrada;

- $\bar{y}$ : Preparações para produção realizadas na solução atual.

Os valores das soluções são, respectivamente, $z^{r}, z^{*}$ e $\bar{z}$.

\subsubsection{Inicialização}

Várias heurísticas foram avaliadas para se obter uma solução inicial para o problema. Testamos o método relax-and-fix (com diferentes tipos de partições), LP-and-fix, e a primeira solução factível encontrada pelo método branch-and-cut. No entanto, os melhores resultados foram obtidos com a heurística descrita a seguir. 
Inicialmente, dividimos o problema em subproblemas, os quais contêm apenas parte dos períodos do horizonte de planejamento do problema original. Cada período de produção deve estar presente somente em um subproblema. Em todos os subproblemas, permitimos a realização de horas extras; no entanto, com custo muito elevado, o que faz esse recurso ser utilizado somente em caso de extrema necessidade. Testes computacionais mostraram que uma boa partição é de 15 períodos consecutivos.

Os subproblemas são resolvidos pelo software CPLEX. A cada solução obtida, descartamos as horas extras e armazenamos as variáveis de preparação para produção da solução na partição correspondente do problema original. Ao fim do processo, resolvemos o problema original com todas as variáveis de preparação de máquina fixadas como ilustra a Figura 4.1. Destacamos que, devido a possibilidade de utilizar horas extras, a solução inicial obtida pode não ser factível para o problema original, no entanto é uma solução com características de boa qualidade. No Algoritmo 7, resumimos a heurística de inicialização.

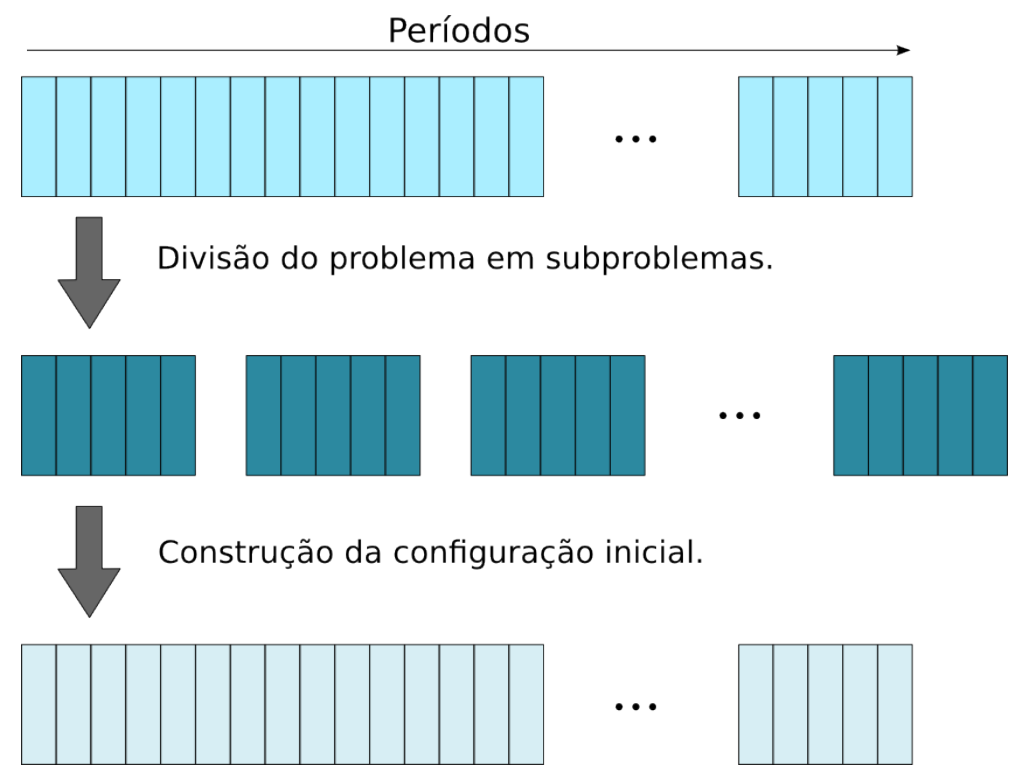

Figura 4.1: Processo de construção da solução inicial.

\subsubsection{Busca tabu com memória de curto prazo}

A busca tabu com memória de curto prazo proposta é dividida em duas partes. A primeira compreende a resolução do problema linearmente relaxado modificado, cuja solução será utilizada para redução da vizinhança de busca. Na segunda parte, é resolvido um problema inteiro modificado que escolhe na vizinhança reduzida uma solução factível.

Mais detalhadamente, a primeira parte consiste em relaxar linearmente o problema original e acrescentar a ele duas restrições. Estas restrições fazem parte da memória tabu, ou seja, evitam que ocorra ciclagem. A primeira restrição faz com que ao menos uma das preparações de máquina que ocorreu na última solução factível encontrada não ocorra. Especificamente, considere o conjunto $S=\left\{(t, m, p), \forall \bar{y}_{t m p}=1\right\}$; então, a primeira restrição é dada: 


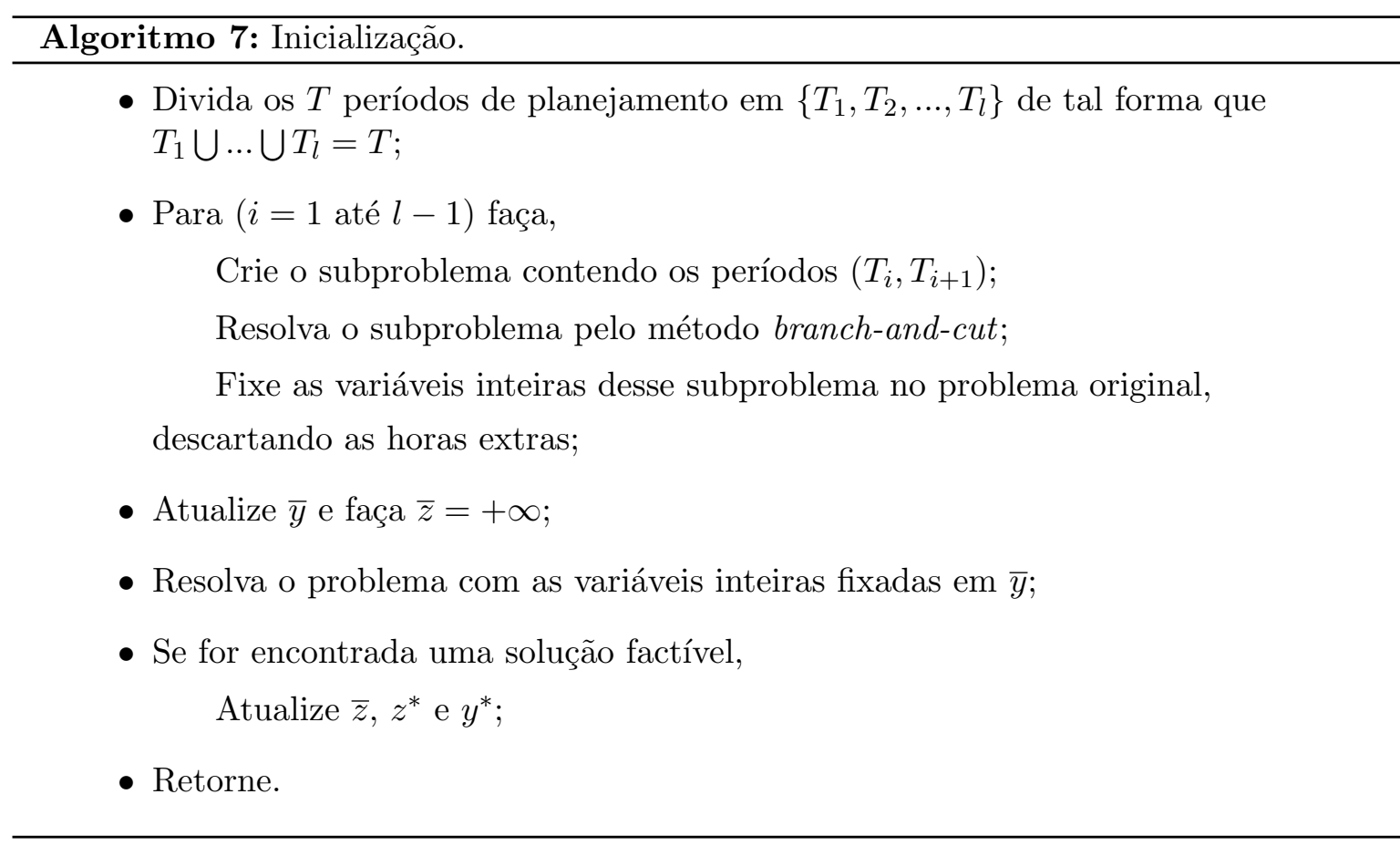

$$
\sum_{(t, m, p) \in S} y_{t m p} \leq|S|-1
$$

A segunda restrição garante que as preparações de máquina que foram realizadas na solução atual e não foram realizadas na solução factível anterior continuem sendo realizadas, evitando, assim, que movimentos feitos mais recentemente sejam desfeitos. Para definir essa restrição, considere o conjunto $T^{d r o p}=\{(t, m, p)$ : se a preparação de máquina ocorre na solução atual e não ocorre na solução anterior\}, ou seja, é o conjunto que representa as preparações de máquina que foram habilitadas mais recentemente. A partir desse conjunto, definimos a seguinte restrição:

$$
y_{\text {tmp }}=1, \forall(t, m, p) \in T^{d r o p} .
$$

Essas restrições são acrescentadas ao problema, que é então resolvido de forma relaxada (linear) pelo software CPLEX. Existe a possibilidade de não encontrarmos uma solução factível para o problema relaxado. Quando isso ocorre, removemos as restrições 4.6 e 4.7) e, então, exigimos apenas que uma parte das variáveis pertencentes a $T^{d r o p}$ se mantenha ativa. Essa estratégia faz parte do critério de aspiração adotado na busca e é definida por:

$$
\sum_{(t, m, p) \in T^{d r o p}} y_{t m p} \geq\left|T^{d r o p}\right|-\gamma
$$

O valor inicial de $\gamma$ é $\left|T^{\text {drop }}\right| / 4$. No entanto, caso uma solução factível seja obtida, ele é aumentado tendo como limite superior o valor $\left|T^{d r o p}\right|-1$. O Algoritmo 8 apresenta o processo de resolução do problema relaxado.

Uma vez obtida a solução podemos seguir para a segunda parte da busca na vizinhança. 


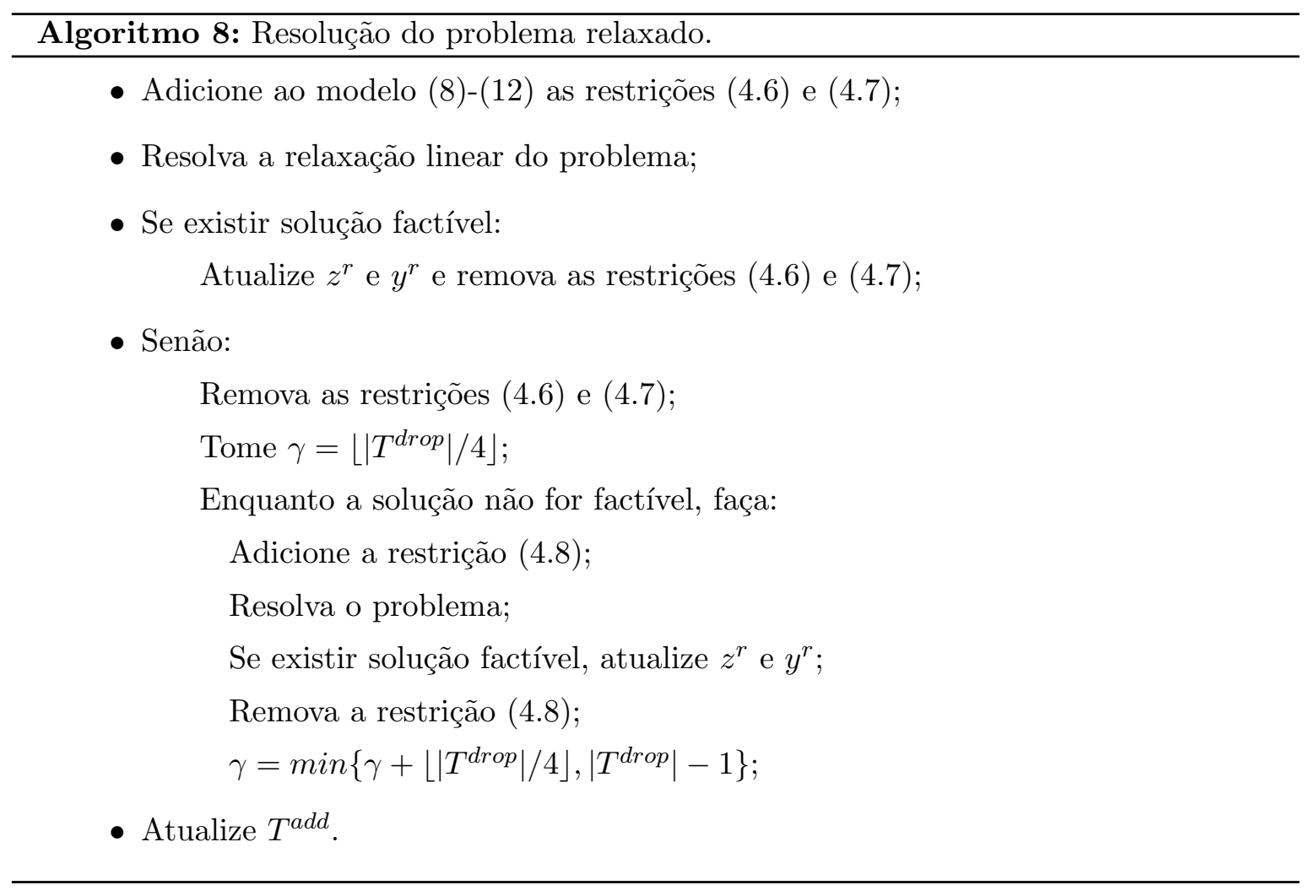

Nessa etapa do processo, nosso objetivo é encontrar uma nova solução inteira factível para o problema original, impondo dois grupos de restrições adicionais. O primeiro grupo de restrições define a vizinhança para a busca tabu. Primeiramente, considere os conjuntos $S_{0}^{\prime}$ $=\left\{(t, m, p): \forall\left(y_{t m p}^{r}=0\right.\right.$ e $\left.\left.\bar{y}_{t m p}=0\right)\right\}$ e $S_{1}^{\prime}=\left\{(t, m, p): \forall\left(y_{t m p}^{r}=1\right.\right.$ e $\left.\left.\bar{y}_{t m p}=1\right)\right\}$. Então, as restrições são dadas por:

$$
\begin{aligned}
& y_{t m p}=0, \forall(t, m, p) \in S_{0}^{\prime} \\
& y_{t m p}=1, \forall(t, m, p) \in S_{1}^{\prime} .
\end{aligned}
$$

Essas restrições limitam o domínio de busca do problema fixando parte das variáveis que são inteiras. Nesse ponto, podemos ver claramente a importância de o problema ter uma relaxação linear de boa qualidade.

O segundo grupo de restrições ajuda a evitar a ciclagem. Com as restrições, garantimos que as preparações de máquina que são ativas na solução atual e não são ativas na solução relaxada não se tornem novamente todas ativas na nova solução. Para auxiliar na formulação dessa restrição, considere o conjunto $T^{a d d}=\left\{(t, m, p): y_{t m p}^{r} \neq 1\right.$ e $\left.\bar{y}_{t m p}=1\right\}$, que indica as preparações de máquina que são ativas na solução corrente, e não são ativas na solução relaxada. A restrição é dada por:

$$
\sum_{(t, m, p) \in T^{a d d}} y_{t m p} \leq\left|T^{a d d}\right|-1
$$


A fim de manter parte do histórico da busca, a restrição é incluída para os cinco últimos movimentos da busca, ou seja,

$$
\sum_{(t, m, p) \in T_{k}^{a d d}} y_{t m p} \leq\left|T_{k}^{a d d}\right|-1
$$

em que $k=1, \ldots, 5$

Com a adição das restrições (4.9), (4.10) e (4.12) ao problema original (8)-(12), podemos comprometer sua factibilidade. Nesse caso, para que a busca continue, a solução relaxada do problema é adotada como solução atual $\bar{y}$, e, para o próximo problema restrito a ser resolvido, o conjunto $S_{0}$ é tomado como nulo. Assim, a busca prossegue. Esse procedimento é realizado com a esperança de que, ao final da próxima iteração da busca, seja possível obter uma solução inteira factível.

Mesmo com a adição da restrição (4.9) e 4.10) ao modelo, que limita razoavelmente o espaço de busca, a resolução do problema restrito pode ter um tempo computacional elevado. Para contornar esse fato, a cada iteração atualizamos o desvio de otimalidade aceito pelo software como critério de parada. Este desvio é atualizado com o objetivo de tornar o tempo de execução da memória de curto prazo próximo ao um limiar de tempo $\tau$, que é adotado como 15 segundos ( $5 \%$ do tempo total do método). O desvio máximo, dsv max , aceito é de 10\%. Se o tempo de execução do problema restrito ultrapassa 40 segundos, a resolução do problema restrito é interrompida e a busca segue com a solução obtida nesse tempo. O Algoritmo 9 ilustra o processo. O conjunto $T^{\text {freq }}$ armazena a frequência que cada preparação de máquina aparece nas soluções factíveis encontradas durante o processo de busca. Essa estrutura é utilizada pela da memória de longo prazo e é definida com mais detalhes nas Subseções 4.2 .3 e 4.2 .4

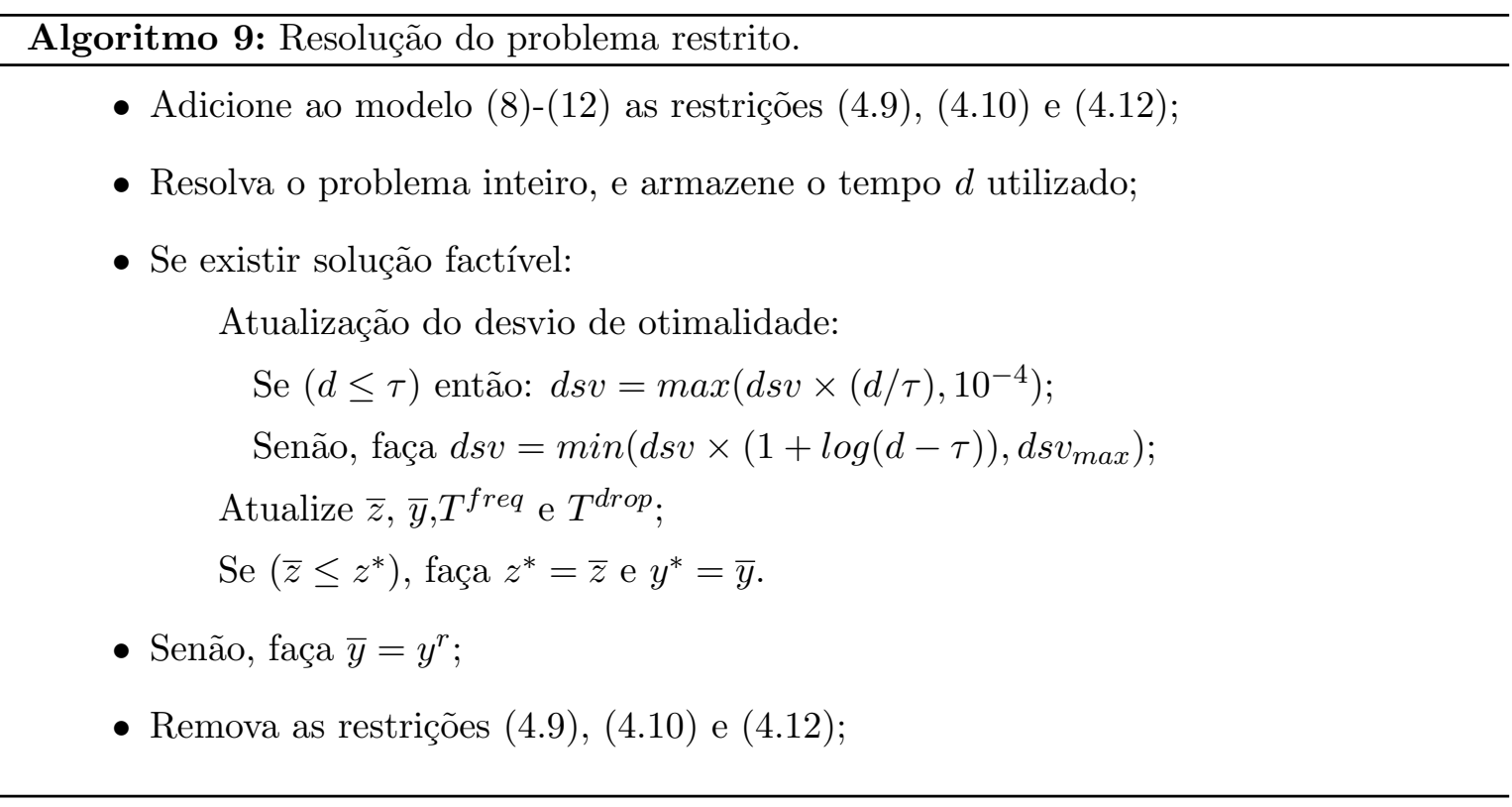




\subsubsection{Intensificação}

Utilizar somente estruturas de memória de curto prazo pode fazer com que a convergência da busca tabu para soluções com baixos desvios de otimalidade seja lenta. Para contornar esse fato, adicionamos estruturas de memória de logo prazo como intensificação e diversificação.

A intensificação utilizada é baseada na frequência com que as preparações de máquina são ativas ou não nas soluções factíveis encontradas pela busca tabu. A intensificação é feita fixando como ativas as preparações de máquina que mais ocorrem e como inativas as que menos ocorrem.

Seja $r$ o número de soluções inteiras factíveis encontradas durante o processo de busca, então definimos os conjuntos:

- $G_{0}=\left\{(t, m, p):\left(T_{t m p}^{f r e q} \leq \beta \times r\right)\right.$ e $\left.\left(y_{t m p}^{*}=0\right)\right\}$, conjunto das preparações de máquina que permanecem inativas por, pelo menos, um certo número de iterações e são inativas na melhor solução encontrada durante o processo de busca;

- $G_{1}=\left\{(t, m, p):\left(T_{t m p}^{f r e q} \geq \rho \times r\right)\right.$ e $\left.\left(y_{t m p}^{*}=1\right)\right\}$, conjunto das preparações de máquina que permanecem ativas por, pelo menos, um dado número de iterações e são ativas na melhor solução encontrada durante o processo de busca.

As constantes $\rho$ e $\beta$ em $G_{1}$ e $G_{0}$ são definidas de forma que estejam contidas no intervalo $[0,1], \rho$ seja estritamente maior que $\beta$ e $\left|G_{1} \cup G_{0}\right|$ seja o menor valor maior que um valor $L$ pré-estabelecido. Baseado em testes computacionais, $L$ é, inicialmente, igual a $90 \%$ do número de variáveis inteiras do problema $(N \times M \times T)$ e é reajustado a cada iteração da intensificação de acordo com o tempo utilizado na resolução do problema nessa fase.

Com esses conjuntos, definimos as equações 4.13) e 4.14 para fixar parte das variáveis do problema:

$$
\begin{aligned}
& y_{t m p}=0, \forall(t, m, p) \in\left\{G_{0}\right\} \\
& y_{t m p}=1, \forall(t, m, p) \in\left\{G_{1}\right\}
\end{aligned}
$$

As variáveis que continuam livres após essa fixação definem a vizinhança de busca da fase de intensificação. Como o objetivo da intensificação é encontrar uma solução de melhor qualidade que outras já obtidas, impomos que a solução tenha melhor qualidade que a melhor solução já encontrada, ou seja,

$$
\sum_{i=1}^{N} \sum_{m=1}^{M} \sum_{t=1}^{T} \sum_{r=1}^{t-1}(t-r) h_{i} X_{i m t r}+\sum_{i=1}^{N} \sum_{m=1}^{M} \sum_{t=1}^{T} \sum_{r=t+1}^{T}(r-t) h b_{i} X_{i m t r}+\sum_{i=1}^{N} \sum_{m=1}^{M} \sum_{t=1}^{T} s_{i m} Y_{i m t}<z^{*}
$$

Essa restrição é adicionada com o intuito de agilizar a resolução do problema durante a intensificação. Assim, introduzimos ao problema um limitante superior e, então, todas as soluções que não são o foco da busca são excluídas. O Algoritmo 10 apresenta o processo de intensificação. 


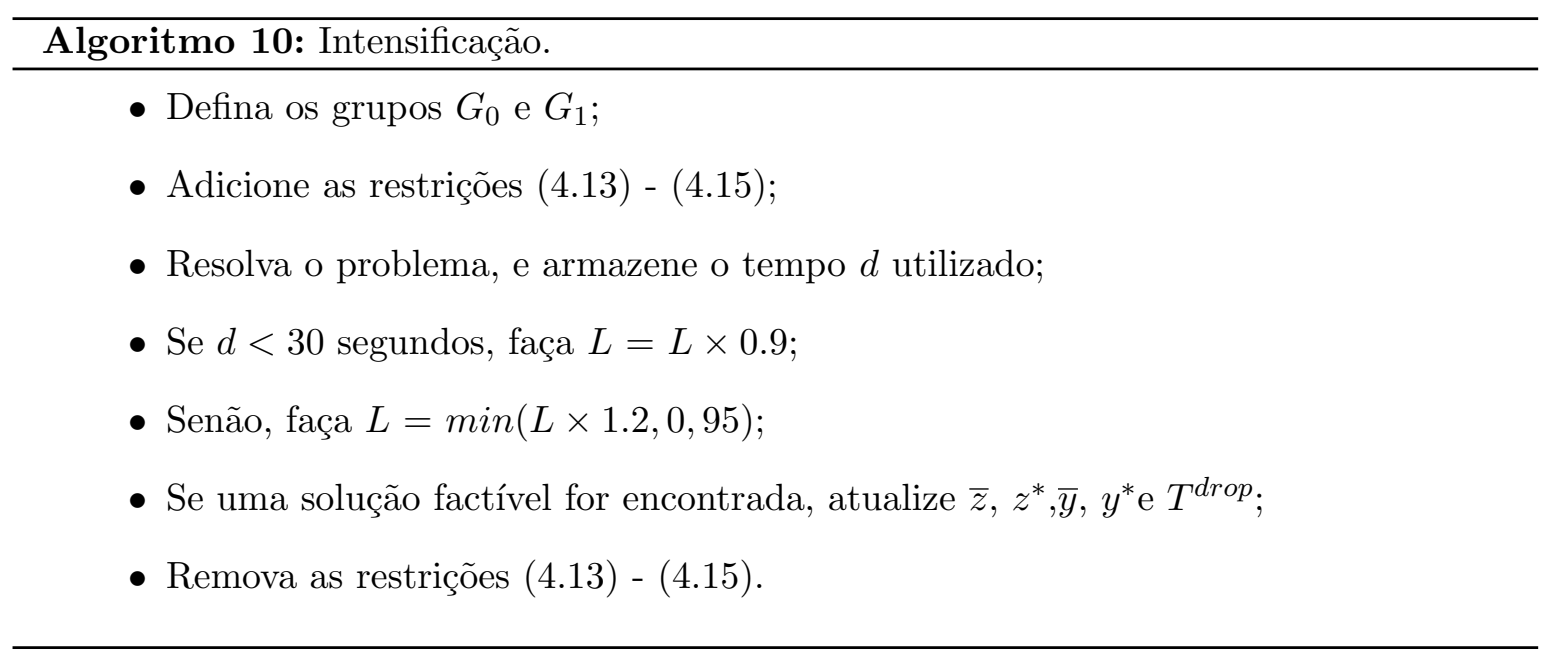

\subsubsection{Diversificação}

O processo de diversificação utilizado é, assim como na intensificação, baseado na frequência com a qual as preparações de máquina ocorrem ou não em soluções factíveis do problema encontradas durante o processo de busca. Basicamente, ela é realizada exigindo que algumas das preparações de máquina que ocorrem com menor frequência durante o processo de busca ocorram na solução diversificada.

Mais detalhadamente, considere o conjunto $Q$ das preparações de máquina ativas na solução de melhor qualidade encontrada durante o processo de busca. Então, definimos o conjunto $H=\left\{(t, m, p): T_{t m p}^{f r e q} \leq h \times r\right\}$, em que $h$ é o menor valor no intervalo [0,1] tal que $|H| \geq|Q| \times 0,2$. Ou seja, criamos um conjunto das preparações de máquina que menos ocorrem durante o processo de busca. A partir desse conjunto, definimos uma restrição que exige que algumas preparações de máquina que ocorreram com pouca frequência durante o processo de busca sejam ativas na solução diversificada. A restrição é dada por:

$$
\sum_{(t, m, p) \in H} y_{t m p} \geq|Q| \times \kappa
$$

O parâmetro $\kappa$ é inicialmente definido como 0,2 . A restrição pode tornar o problema infactível. Quando isso ocorre, voltamos para a memória de curto prazo e atualizamos o valor de $\kappa$ para $\kappa / 2$.

Como o objetivo da diversificação é encontrar soluções que sejam distintas das já visitadas pelo processo de busca, resolvemos o problema inteiro modificado utilizando o desvio de otimalidade máximo. O Algoritmo 11 resume o processo de diversificação.

\subsubsection{Busca tabu com vizinhança abrangente (BTVA)}

O método híbrido proposto tem como critério de parada o tempo limite de 300 segundos. Além disso, testes computacionais preliminares mostraram que um bom limitante de iterações para a memória de curto prazo é 20, ou 8 iterações consecutivas sem melhoria na solução. O Algoritmo 12 resume a busca tabu com vizinhança abrangente (BTVA) e a Figura 4.2 ilustra 


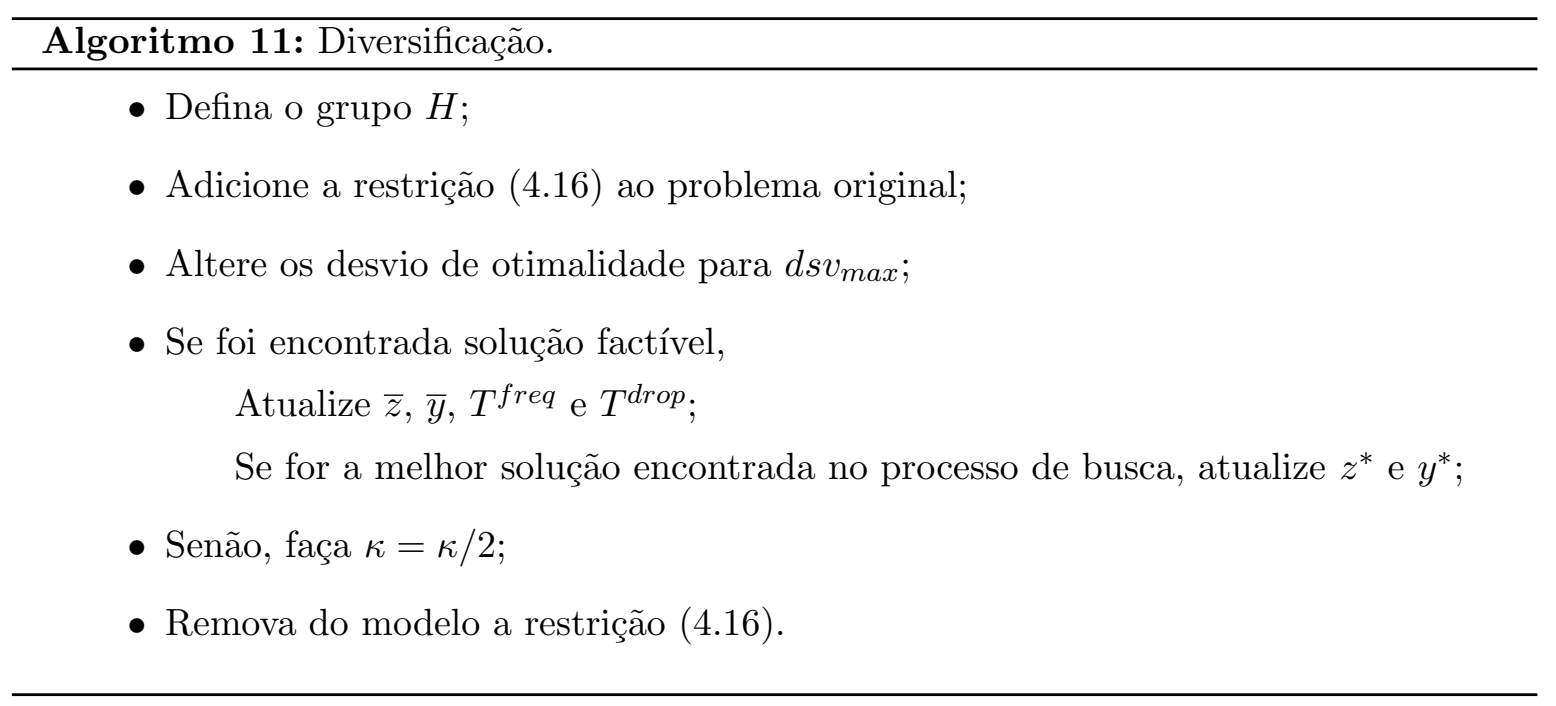

um fluxograma da BTVA.

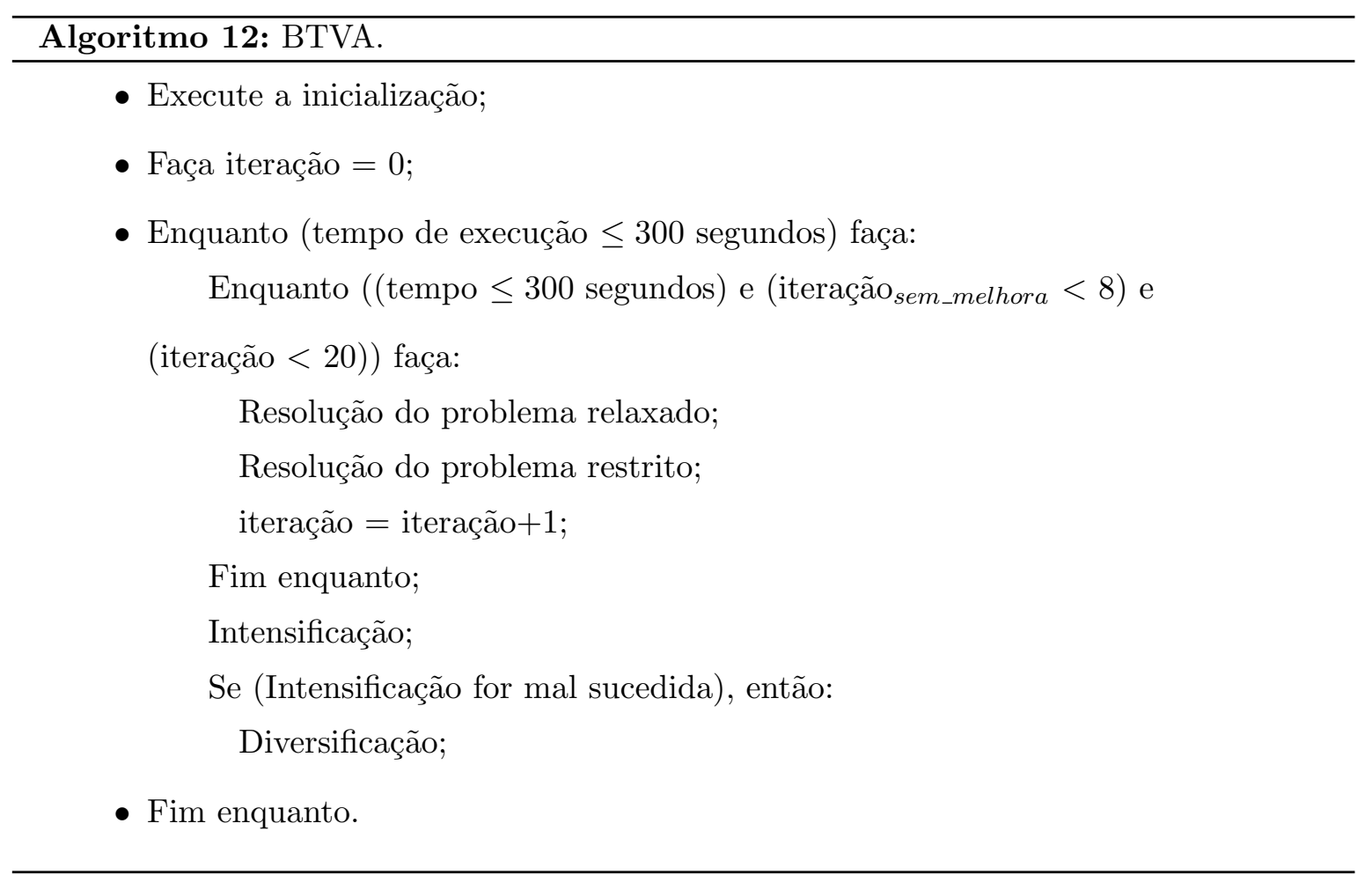

\subsection{Testes computacionais}

Para realizar os testes computacionais, o método híbrido apresentado foi codificado em linguagem $\mathrm{C} / \mathrm{C}++$ e os testes foram conduzidos num computador com processador Intel Core 2 Quad $3.00 \mathrm{GHz}$ com 4 Gb de memória e sistema operacional Ubuntu 12.04 (64 bits). O tempo limite de cinco minutoß $\bigsqcup^{1}$ foi imposto para resolução dos problemas. Para todos os

\footnotetext{
${ }^{1} \mathrm{O}$ tempo de 5 minutos forneceu os limitantes inferiores para o cálculo dos desvios. As instâncias são as mesmas utilizadas no Capítulo 3 Na Tabela 4.1. apresentamos os desvios obtidos pelos métodos para as
} 


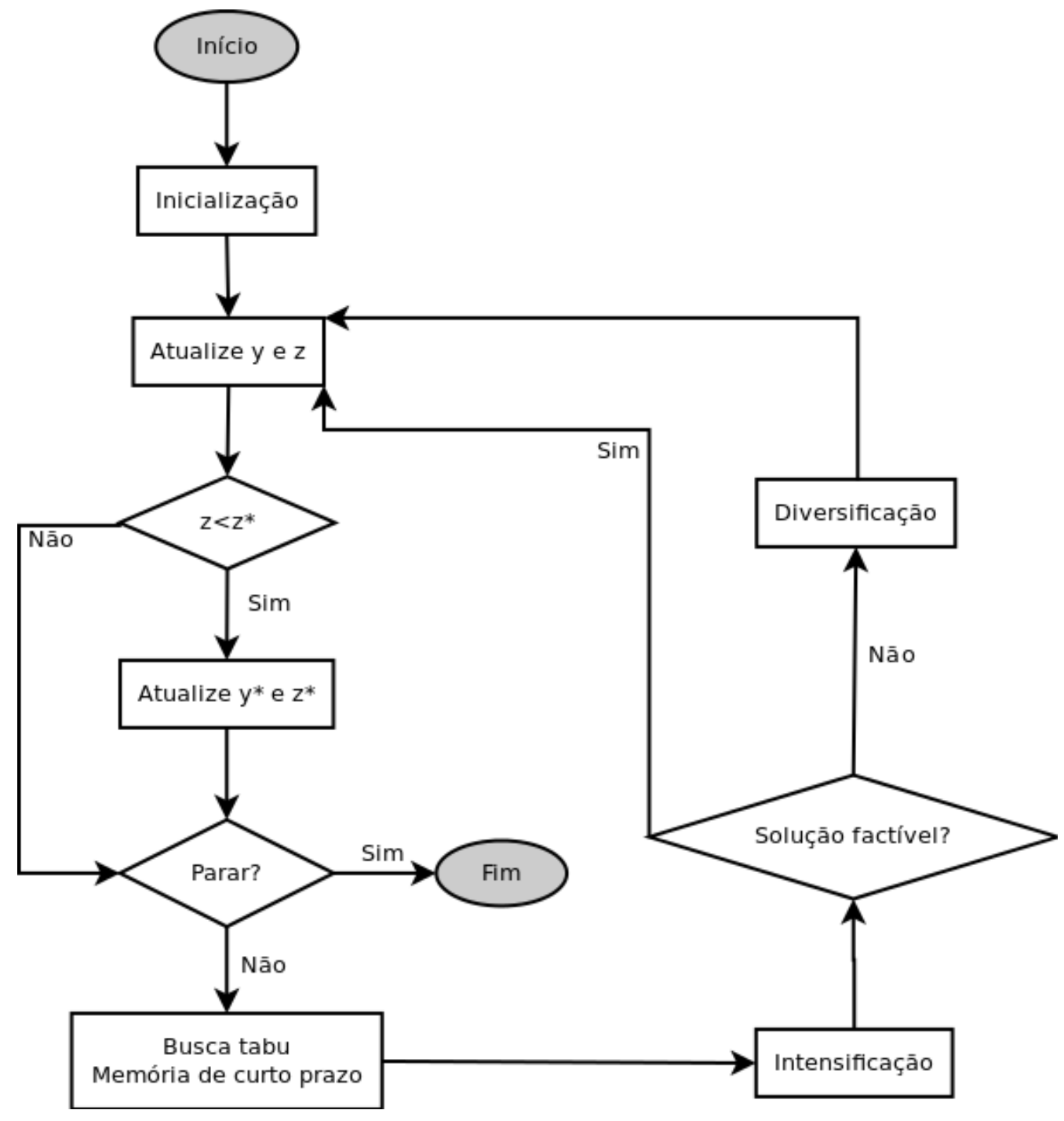

Figura 4.2: Fluxograma da BTVA.

conjuntos de instâncias utilizados, foi calculado o desvio percentual entre a solução obtida e o limitante inferior da solução fornecido pelo software CPLEX 12.1. Esse desvio é calculado da seguinte maneira:

$$
\text { Desvio }=\frac{\mid(\text { Solução Heurística })-(\text { Limitante CPLEX }) \mid}{(\text { Limitante CPLEX })} \times 100 .
$$

Na Subseção 4.3.1, comparamos o método BTVA com a heurística BTD+ID apresentada no Capítulo 3, com o intuito de avaliar seus desempenhos na resolução de problemas de dimensionamento de lotes em que é permitido o atraso na produção para atender a demanda. Na Subseção 4.3.2, são apresentados os resultados computacionais para instâncias em que não é permitido o atraso na produção para atender a demanda. Assim temos a possibilidade

instâncias foi adotado, pois os resultados serão comparados aos apresentados em Muller et al. (2012) com o mesmo tempo em uma máquina similar à utilizada segundo a análise da Standard Performance Evaluation Corporation (www.spec.org/). 
de comparar nossos resultados com outros trabalhos da literatura.

\subsubsection{Instâncias com possibilidade de atraso na entrega}

A fim de comparar o método proposto com a melhor heurística apresentada no Capítulo 3. realizamos testes computacionais em que é permitido o atraso na entrega dos produtos. Os métodos avaliados foram: BTVA e BTD+ID. Também resolvemos essas instâncias utilizando o software CPLEX 12.1 a partir da formulação baseada em localização de facilidades Krarup e Bilde, 1977), a qual também forneceu os limitantes inferiores para o cálculo dos desvios. As instâncias são as mesmas utilizadas no Capítulo 3. Na Tabela 4.1, apresentamos os desvios obtidos pelos métodos para as instâncias de Trigeiro et al. (1989). Nas Tabelas 4.2 e 4.3 são apresentados os desvios obtidos para as instâncias de Muller et al. (2012) referentes às instâncias heterogêneas e homogêneas, respectivamente. A coluna CPLEX apresenta os desvios obtidos pelo CPLEX na resolução do problema. Os desvios do método BTVA são apresentados em duas colunas, nas quais a primeira (Solução inicial) representa a solução obtida pela inicialização do método e a segunda (Solução final), a solução obtida ao fim do processo de busca. Os desvios da heurística BTD+ID são apresentados na última coluna.

Tabela 4.1: Resultados obtidos para as instâncias adaptadas de Trigeiro et al. (1989).

\begin{tabular}{l|cccc}
\hline & & \multicolumn{3}{|c}{ BTVA } \\
\cline { 3 - 4 } & CPLEX & Solução inicial & Solução final & BTD+ID \\
\hline G51-G55 & $0,0 \%$ & $9,3 \%$ & $0,0 \%$ & $1,1 \%$ \\
\hline G56-G60 & $0,0 \%$ & $7,3 \%$ & $0,0 \%$ & $2,1 \%$ \\
\hline G66-G70 & $0,0 \%$ & $1,2 \%$ & $0,0 \%$ & $1,9 \%$ \\
\hline G71-G75 & $0,0 \%$ & $1,1 \%$ & $0,0 \%$ & $2,6 \%$ \\
\hline Média & $\mathbf{0 , 0 \%}$ & $\mathbf{4 , 7 \%}$ & $\mathbf{0 , 0 \%}$ & $\mathbf{1 , 9 \%}$ \\
\hline
\end{tabular}

Tabela 4.2: Resultados obtidos para as instâncias heterogêneas adaptadas de Muller et al. (2012).

\begin{tabular}{|c|c|c|c|c|}
\hline & \multicolumn{4}{|c|}{ BTVA } \\
\hline & CPLEX & Solução inicial & Solução Final & $\mathrm{BTD}+\mathrm{ID}$ \\
\hline $\mathrm{G} 51^{30}-\mathrm{G} 55^{30}$ & $4,0 \%$ & $7,6 \%$ & $4,2 \%$ & $35,2 \%$ \\
\hline $\mathrm{G} 56^{30}-\mathrm{G} 60^{30}$ & $4,4 \%$ & $9,2 \%$ & $4,4 \%$ & $38,4 \%$ \\
\hline $\mathrm{G} 66^{60}-\mathrm{G} 70^{60}$ & $9,9 \%$ & $15,2 \%$ & $9,9 \%$ & $43,5 \%$ \\
\hline $\mathrm{G} 71^{60}-\mathrm{G} 75^{60}$ & $11,2 \%$ & $14,6 \%$ & $11,1 \%$ & $59,4 \%$ \\
\hline $\mathrm{G} 51^{45}-\mathrm{G} 55^{45}$ & $6,4 \%$ & $11,3 \%$ & $6,7 \%$ & $39,4 \%$ \\
\hline $\mathrm{G} 56^{45}-\mathrm{G} 60^{45}$ & $5,4 \%$ & $11,6 \%$ & $5,7 \%$ & $49,0 \%$ \\
\hline $\mathrm{G} 66^{90}-\mathrm{G} 70^{90}$ & $12,4 \%$ & $15,8 \%$ & $12,7 \%$ & $55,0 \%$ \\
\hline $\mathrm{G} 71^{90}-\mathrm{G} 75^{90}$ & $14,4 \%$ & $15,2 \%$ & $12,5 \%$ & $79,1 \%$ \\
\hline Média & $8,5 \%$ & $12,6 \%$ & $8,4 \%$ & $49,9 \%$ \\
\hline
\end{tabular}

Note que os desvios obtidos pela heurística BTD+ID são diferentes dos apresentados no Capítulo 3 pois, apesar de o limitante inferior utilizado no cálculo dos desvios ainda ser 
Tabela 4.3: Resultados obtidos para as instâncias homogêneas adaptadas de Muller et al. (2012).

\begin{tabular}{|c|c|c|c|c|}
\hline & \multirow[b]{2}{*}{ CPLEX } & \multicolumn{2}{|c|}{ BTVA } & \multirow[b]{2}{*}{$\mathrm{BTD}+\mathrm{ID}$} \\
\hline & & Solução inicial & Solução Final & \\
\hline $\mathrm{HG}^{2} 1^{30}-\mathrm{HG} 55^{30}$ & $3,0 \%$ & $13,2 \%$ & $3,1 \%$ & $24,6 \%$ \\
\hline $\mathrm{HG} 56^{30}-\mathrm{HG} 60^{30}$ & $3,2 \%$ & $17,2 \%$ & $3,6 \%$ & $65,9 \%$ \\
\hline HG66 $6^{60}-\mathrm{HG}^{6} 0^{60}$ & $8,9 \%$ & $18,7 \%$ & $8,9 \%$ & $51,2 \%$ \\
\hline $\mathrm{HG}_{71}^{60}-\mathrm{HG} 75^{60}$ & $10,6 \%$ & $17,8 \%$ & $10,5 \%$ & $113,5 \%$ \\
\hline HG5 $1^{45}-\mathrm{HG} 55^{45}$ & $1,6 \%$ & $8,8 \%$ & $1,7 \%$ & $15,2 \%$ \\
\hline $\mathrm{HG}_{5} 6^{45}-\mathrm{HG} 60^{45}$ & $2,4 \%$ & $12,6 \%$ & $2,7 \%$ & $57,5 \%$ \\
\hline HG66 $6^{90}-\mathrm{HG} 70^{90}$ & $7,1 \%$ & $16,5 \%$ & $7,2 \%$ & $70,5 \%$ \\
\hline $\mathrm{HG}_{71}{ }^{90}-\mathrm{HG} 75^{90}$ & $7,3 \%$ & $15,5 \%$ & $7,0 \%$ & $102,3 \%$ \\
\hline Média & $5,5 \%$ & $15,1 \%$ & $5,6 \%$ & $62,6 \%$ \\
\hline
\end{tabular}

fornecido pelo software CPLEX, a formulação utilizada está baseada em Krarup e Bilde (1977) e não na formulação padrão como anteriormente. Portanto, os limitantes são distintos. Os resultados obtidos pela heurística BTD+ID são de baixa qualidade, sendo inferiores à solução inicial do método BTVA para todas as instâncias de Muller et al. (2012).

Pudemos notar que tanto o software CPLEX quanto o método BTVA conseguem obter os menores desvios para as instâncias de Trigeiro et al. (1989). Para as instâncias de Muller et al. (2012), os desvios obtidos pelo software CPLEX e pelo método BTVA são competitivos. Além disso, analisando a primeira solução e a solução final encontradas pelo método BTVA, podemos notar uma grande melhoria na qualidade da solução. Isso mostra que o procedimento de busca tabu realmente tem sucesso na busca por melhores soluções.

Tabela 4.4: Resultados obtidos para as instâncias com múltiplas máquinas adaptadas de Toledo e Armentano (2006).

\begin{tabular}{l|cccc} 
& & \multicolumn{3}{|c}{ BTVA } \\
\cline { 2 - 4 } & CPLEX & Solução inicial & Solução Final & BTD+ID \\
\hline $\mathrm{T} 1^{4,6}-\mathrm{T} 5^{4,6}$ & $0,0 \%$ & $0,0 \%$ & $0,0 \%$ & $0,2 \%$ \\
\hline $\mathrm{T} 1^{4,12}-\mathrm{T} 5^{4,12}$ & $0,2 \%$ & $1,5 \%$ & $0,3 \%$ & $0,7 \%$ \\
\hline $\mathrm{T} 1^{4,18}-\mathrm{T} 5^{4,18}$ & $0,5 \%$ & $0,7 \%$ & $0,5 \%$ & $0,9 \%$ \\
\hline $\mathrm{T} 6^{4,6}-\mathrm{T} 10^{4,6}$ & $0,0 \%$ & $0,0 \%$ & $0,0 \%$ & $0,8 \%$ \\
\hline $\mathrm{T} 6^{4,12}-\mathrm{T} 10^{4,12}$ & $0,0 \%$ & $0,0 \%$ & $0,0 \%$ & $1,1 \%$ \\
\hline $\mathrm{T} 6^{4,18}-\mathrm{T} 10^{4,18}$ & $0,0 \%$ & $0,1 \%$ & $0,0 \%$ & $0,7 \%$ \\
\hline $\mathrm{T} 1^{6,6}-\mathrm{T} 5^{6,6}$ & $0,0 \%$ & $0,0 \%$ & $0,0 \%$ & $0,2 \%$ \\
\hline $\mathrm{T} 1^{6,12}-\mathrm{T} 5^{6,12}$ & $0,2 \%$ & $0,3 \%$ & $0,2 \%$ & $0,7 \%$ \\
\hline $\mathrm{T} 1^{6,18}-\mathrm{T} 5^{6,18}$ & $0,4 \%$ & $0,6 \%$ & $0,5 \%$ & $0,6 \%$ \\
\hline $\mathrm{T} 6^{6,6}-\mathrm{T} 10^{4,6}$ & $0,0 \%$ & $0,0 \%$ & $0,0 \%$ & $0,2 \%$ \\
\hline $\mathrm{T} 6^{6,12}-\mathrm{T} 10^{4,12}$ & $0,1 \%$ & $0,1 \%$ & $0,1 \%$ & $0,8 \%$ \\
\hline $\mathrm{T} 6^{6,18}-\mathrm{T} 10^{4,18}$ & $0,1 \%$ & $0,2 \%$ & $0,1 \%$ & $0,6 \%$ \\
\hline Média & $\mathbf{0 , 1 \%}$ & $\mathbf{0 , 3 \%}$ & $\mathbf{0 , 1 \%}$ & $\mathbf{0 , 6 \%}$ \\
\hline
\end{tabular}

Como mostra a Tabela 4.4 para múltiplas máquinas, os desvios apresentados pelas soluções obtidas pelo método BTVA e pelo software CPLEX são os menores obtidos, não havendo diferenças significativas entre eles. As diferenças entre as soluções inicial e final 
encontradas pela método BTVA são menos significativas que para os testes anteriores. Isso porque os problemas atingem desvios de baixa magnitude em baixo tempo computacional. A heurística BTD+ID, apesar de apresentar desvios com baixa magnitude, obtém os maiores desvios para todas as instâncias com múltiplas máquinas.

\subsubsection{Instâncias sem possibilidade de atraso na produção}

Primeiramente, apresentamos os resultados computacionais para problemas que contemplam o planejamento de produção com uma máquina. Todas as instâncias utilizadas foram apresentadas na Seção 3.4.1. Na Tabela 4.5, os desvios são referentes às instâncias de Trigeiro et al. (1989).

Tabela 4.5: Resultados para as instâncias de Trigeiro et al.(1989).

\begin{tabular}{l|ccc}
\hline & & \multicolumn{2}{c}{ BTVA } \\
\cline { 3 - 4 } & CPLEX & Solução inicial & Solução final \\
\hline G51-G55 & $0,0 \%$ & $1,3 \%$ & $0,0 \%$ \\
\hline G56-G60 & $0,0 \%$ & $0,7 \%$ & $0,0 \%$ \\
\hline G66-G70 & $0,0 \%$ & $11,5 \%$ & $0,0 \%$ \\
\hline G71-G75 & $0,0 \%$ & $16,9 \%$ & $0,0 \%$ \\
\hline Média & $\mathbf{0 , 0 \%}$ & $\mathbf{7 , 6 \%}$ & $\mathbf{0 , 0 \%}$ \\
\hline
\end{tabular}

Mesmo sem considerar a possibilidade de atraso na produção, o método resulta em desvios iguais ou muito próximos aos obtidos pelo software. Ainda, focando nos resultados obtidos pelo método BTVA, a qualidade dos desvios obtidos nas soluções iniciais é muito pobre quando comparada à das soluções finais.

Nas Tabelas 4.6 e 4.7, apresentamos os desvios obtidos, respectivamente, para as instâncias heterogêneas e homogêneas apresentadas em Muller et al. (2012). Nas tabelas, além das colunas já definidas, adicionamos a coluna ALNS que apresenta os desvios obtidos em Muller et al. (2012).

Tabela 4.6: Resultados para as instâncias heterogêneas de Muller et al. (2012).

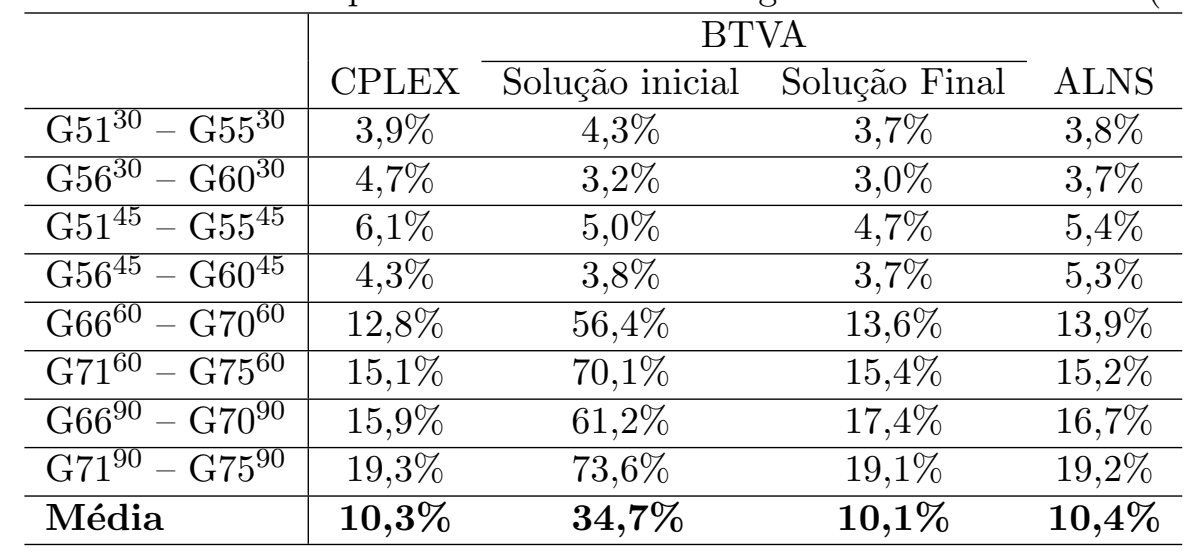

Os desvios para os problemas homogêneos se mostraram maiores que os dos problemas heterogêneos, o que já era esperado devido à maior dificuldade do problema. Os métodos BTVA e ALNS e o software CPLEX obtêm soluções com desvios muito próximos, sendo que 
Tabela 4.7: Resultados para as instâncias homogêneas de Muller et al. (2012).

\begin{tabular}{|c|c|c|c|c|}
\hline & \multicolumn{3}{|c|}{ BTVA } & \multirow[b]{2}{*}{ ALNS } \\
\hline & CPLEX & Solução inicial & Solução Final & \\
\hline HG51 $1^{30}-\mathrm{HG} 55^{30}$ & $10,6 \%$ & $12,6 \%$ & $10,1 \%$ & $10,4 \%$ \\
\hline $\mathrm{HG} 56^{30}-\mathrm{HG} 60^{30}$ & $5,4 \%$ & $7,4 \%$ & $5,3 \%$ & $5,7 \%$ \\
\hline $\mathrm{HG} 51^{45}-\mathrm{HG} 55^{45}$ & $13,3 \%$ & $14,4 \%$ & $12,9 \%$ & $13,3 \%$ \\
\hline HG56 $6^{45}-\mathrm{HG} 60^{45}$ & $6,7 \%$ & $6,9 \%$ & $5,8 \%$ & $6,8 \%$ \\
\hline $\mathrm{HG} 66^{60}-\mathrm{HG} 70^{60}$ & $17,5 \%$ & $84,3 \%$ & $18,6 \%$ & $17,1 \%$ \\
\hline $\mathrm{HG} 71^{60}-\mathrm{HG} 75^{60}$ & $16,5 \%$ & $76,6 \%$ & $16,1 \%$ & $16,8 \%$ \\
\hline $\mathrm{HG} 66^{90}-\mathrm{HG} 70^{90}$ & $22,6 \%$ & $86,4 \%$ & $21,1 \%$ & $20,4 \%$ \\
\hline $\mathrm{HG}_{71}{ }^{90}-\mathrm{HG} 75^{90}$ & $20,8 \%$ & $78,6 \%$ & $19,0 \%$ & $20,5 \%$ \\
\hline Média & $14,2 \%$ & $45,9 \%$ & $13,6 \%$ & $13,9 \%$ \\
\hline
\end{tabular}

a matheurística BTVA fornece, na média, desvios ligeiramente melhores. Em todos os casos, a qualidade da solução inicial encontrada pela BTVA é baixa. Ainda, pode-se notar que os desvios obtidos pela BTVA são, na maioria dos casos, os menores quando comparados aos desvios dos outros métodos.

Os resultados mostram que o método BTVA é competitivo com a heurística ALNS para esse tipo de problema.

A fim de verificar o desempenho das heurísticas para problemas que contemplam a produção em máquinas paralelas, utilizamos dois conjuntos de instâncias. O primeiro foi proposto em Toledo e Armentano (2006) e já foi apresentado na Seção 3.4.2. O segundo foi gerado a partir das instâncias utilizadas em Muller et al. (2012). Para isso, mantemos todos os dados da instância alterando apenas o número de máquinas e suas respectivas capacidades de acordo com Toledo e Armentano (2006). As capacidades das máquinas são calculadas da seguinte maneira:

Capacidade $=($ Capacidade original $) /($ número de máquinas $) ;$

Capacidade $_{\text {ajustada }}=(1,18-0,07 M) \times$ Capacidade.

O conjunto de instâncias é nomeado da mesma forma que as instâncias de Muller et al. (2012), porém, agora, acrescentando o prefixo '2' à sua nomenclatura.

Os resultados obtidos para o primeiro conjunto de instâncias são apresentados na Tabela 4.8. Nela, os resultados também são comparados com a heurística lagrangeana de Toledo e Armentano (2006). O critério de parada (300s) e o computador utilizado são os mesmos dos demais métodos.

Para as instâncias da Tabela 4.8, nota-se que os desvios obtidos pelos métodos apresentados são de baixa magnitude e nenhum dos métodos é significativamente melhor.

Nas Tabelas 4.9 e 4.10 , apresentamos os resultados computacionais para as instâncias propostas nesta subseção. Note que a inicialização do método BTVA não encontra soluções factíveis para essas instâncias. Em contrapartida, encontra sua solução final factível para todas as instâncias. Além disso, o método BTVA apresenta soluções com desvios menores ou próximos dos fornecidos pelo software CPLEX e, em média, ao final obtivemos desvios 
Tabela 4.8: Resultados para as instâncias de Toledo e Armentano (2006).

\begin{tabular}{|c|c|c|c|c|}
\hline & \multirow[b]{2}{*}{ CPLEX } & \multicolumn{2}{|c|}{ BTVA } & \multirow[b]{2}{*}{$\mathrm{HL}$} \\
\hline & & Solução inicial & Solução final & \\
\hline $\mathrm{T} 1^{4,6}-\mathrm{T} 5^{4,6}$ & $0,00 \%$ & $0,00 \%$ & $0,00 \%$ & $0,07 \%$ \\
\hline $\mathrm{T} 1^{4,12}-\mathrm{T} 5^{4,12}$ & $0,14 \%$ & $0,15 \%$ & $0,14 \%$ & $0,15 \%$ \\
\hline $\mathrm{T} 1^{4,18}-\mathrm{T} 5^{4,18}$ & $0,40 \%$ & $0,64 \%$ & $0,41 \%$ & $0,44 \%$ \\
\hline $\mathrm{T} 6^{4,6}-\mathrm{T} 10^{4,6}$ & $0,00 \%$ & $0,00 \%$ & $0,00 \%$ & $0,07 \%$ \\
\hline $\mathrm{T} 6^{4,12}-\mathrm{T} 10^{4,12}$ & $0,16 \%$ & $0,18 \%$ & $0,18 \%$ & $0,18 \%$ \\
\hline $\mathrm{T} 6^{4,18}-\mathrm{T} 10^{4,18}$ & $0,37 \%$ & $0,72 \%$ & $0,37 \%$ & $0,46 \%$ \\
\hline $\mathrm{T} 1^{6,6}-\mathrm{T} 5^{6,6}$ & $0,00 \%$ & $0,00 \%$ & $0,00 \%$ & $0,00 \%$ \\
\hline $\mathrm{T} 1^{6,12}-\mathrm{T} 5^{6,12}$ & $0,04 \%$ & $0,06 \%$ & $0,05 \%$ & $0,06 \%$ \\
\hline $\mathrm{T} 1^{6,18}-\mathrm{T} 5^{6,18}$ & $0,05 \%$ & $0,29 \%$ & $0,08 \%$ & $0,11 \%$ \\
\hline $\mathrm{T} 6^{6,6}-\mathrm{T} 10^{4,6}$ & $0,03 \%$ & $0,03 \%$ & $0,03 \%$ & $0,04 \%$ \\
\hline $\mathrm{T} 6^{6,12}-\mathrm{T} 10^{4,12}$ & $0,05 \%$ & $0,08 \%$ & $0,07 \%$ & $0,08 \%$ \\
\hline $\mathrm{T} 6^{6,18}-\mathrm{T} 10^{4,18}$ & $0,08 \%$ & $0,30 \%$ & $0,09 \%$ & $0,22 \%$ \\
\hline Média & $0,11 \%$ & $0,20 \%$ & $0,12 \%$ & $0,16 \%$ \\
\hline
\end{tabular}

5,8\% menores para instâncias heterogêneas e 8,8\% menores para instâncias homogêneas. De forma geral, os desvios obtidos são bastante elevados, o que se deve ao grande número de variáveis presentes no problema, sendo este um dos motivos para não gerarmos novas instâncias com mais máquinas para as avaliações. A heurística lagrangeana apresentada por Toledo e Armentano (2006) também foi executada, porém seus desvios são, em média, superiores a 300\%. Desta forma, decidimos exclui-los das análises.

Tabela 4.9: Resultados para as instâncias heterogêneas geradas a partir das instâncias de Muller et al. (2012).

\begin{tabular}{l|ccc} 
& & \multicolumn{2}{c}{ BTVA } \\
\cline { 2 - 4 } & CPLEX & Solução inicial & Solução final \\
\hline $2 \mathrm{G} 51^{30}-\mathrm{G} 55^{30}$ & $38,7 \%$ & - & $38,1 \%$ \\
\hline $2 \mathrm{G} 56^{30}-\mathrm{G} 60^{30}$ & $18,7 \%$ & - & $20,8 \%$ \\
\hline $2 \mathrm{G} 51^{45}-\mathrm{G} 55^{45}$ & $64,6 \%$ & - & $45,0 \%$ \\
\hline $2 \mathrm{G} 56^{45}-\mathrm{G} 60^{45}$ & $28,0 \%$ & - & $24,8 \%$ \\
\hline $2 \mathrm{G} 66^{60}-\mathrm{G} 70^{60}$ & $96,6 \%$ & - & $98,1 \%$ \\
\hline $2 \mathrm{G} 71^{60}-\mathrm{G} 75^{60}$ & $34,7 \%$ & - & $37,4 \%$ \\
\hline $2 \mathrm{G} 66^{90}-\mathrm{G} 70^{90}$ & $158,6 \%$ & - & $138,2 \%$ \\
\hline $2 \mathrm{G} 71^{90}-\mathrm{G} 75^{90}$ & $60,7 \%$ & - & $51,8 \%$ \\
\hline Média & $\mathbf{6 2 , 6 \%}$ & - & $\mathbf{5 6 , 8 \%}$ \\
\hline
\end{tabular}

\subsection{Conclusões}

Neste capítulo, foi proposto um método híbrido que consiste em uma busca tabu com vizinhança de busca abrangente. O método obteve melhor desempenho que as heurísticas apresentadas no Capítulo 3 para instâncias em que o atraso na produção é permitido. Para esses problemas, mostrou-se competitivo quando comparado ao software CPLEX.

Para problemas em que o atraso na produção dos produtos não é permitido, o método 
Tabela 4.10: Resultados para as instâncias homogêneas geradas a partir das instâncias de Muller et al. (2012).

\begin{tabular}{|c|c|c|c|}
\hline & \multirow[b]{2}{*}{ CPLEX } & \multicolumn{2}{|c|}{ BTVA } \\
\hline & & Solução inicial & Solução final \\
\hline $2 \mathrm{HG} 51^{30}-\mathrm{HG} 55^{30}$ & $66,4 \%$ & - & $68,8 \%$ \\
\hline $2 \mathrm{HG} 56^{30}-\mathrm{HG}^{30} 0^{30}$ & $31,2 \%$ & - & $34,8 \%$ \\
\hline $2 \mathrm{HG} 51^{45}-\mathrm{HG} 55^{45}$ & $87,7 \%$ & - & $72,6 \%$ \\
\hline $2 \mathrm{HG} 56^{45}-\mathrm{HG}^{4} 0^{45}$ & $43,1 \%$ & - & $37,1 \%$ \\
\hline $2 \mathrm{HG} 66^{60}-\mathrm{HG} 70^{60}$ & $104,5 \%$ & - & $106,9 \%$ \\
\hline $2 \mathrm{HG} 71^{60}-\mathrm{HG} 75^{60}$ & $51,9 \%$ & - & $54,1 \%$ \\
\hline $2 \mathrm{HG} 66^{90}-\mathrm{HG}^{2} 0^{90}$ & $155,1 \%$ & - & $130,3 \%$ \\
\hline $2 \mathrm{HG} 71^{90}-\mathrm{HG} 75^{90}$ & $95,9 \%$ & - & $61,6 \%$ \\
\hline Média & $79,5 \%$ & - & $70,7 \%$ \\
\hline
\end{tabular}

BTVA se mostrou competitivo quando comparado com outros métodos apresentados na literatura (Muller et al., 2012, Toledo e Armentano, 2006) e com o software CPLEX. Para múltiplas máquinas, o método obteve resultados melhores que os demais.

Vale ressaltar que, em média, o método BTVA é facilmente adaptável a diferentes variações do problema de dimensionamento de lotes, podendo englobar o contexto de múltiplas plantas, a possibilidade de horas extras e atrasos na produção e o aproveitamento de preparação de máquina, entre outras. 


\section{Capítulo 5}

\section{Conclusões}

Nesta dissertação, foi estudado o problema de dimensionamento de lotes que engloba o planejamento de produção de vários produtos em múltiplas máquinas, cujas capacidades de produção são limitadas. O objetivo é encontrar uma solução que minimize a soma dos custos de produção, de estoque, de atrasos e de preparação.

Foram apresentadas meta-heurísticas do tipo busca tabu para a resolução do problema de dimensionamento de lotes. Nosso foco se manteve em dois objetivos principais: a) a investigação sobre como fatores aleatórios podem influenciar na qualidade de soluções obtidas através por heurísticas busca tabu aplicadas ao problema estudado; e b) a proposta de um método híbrido que obtivesse bons resultados em diferentes cenários do problema.

Na primeira etapa, desenvolvemos meta-heurísticas determinísticas baseadas na metaheurística busca tabu aleatória apresentada em Pedroso e Kubo (2005). Com isso, pudemos concluir que a utilização de fatores aleatórios na busca tabu normalmente leva a soluções de pior qualidade quando comparada a heurísticas determinísticas. Além disso, fatores aleatórios podem acarretar em instabilidade quanto à qualidade da solução obtida pela heurística visto que, a cada execução do método, uma solução distinta pode ser encontrada, inconveniente que não é encontrado em métodos determinísticos.

Na segunda etapa, propusemos um método híbrido (matheurística), também baseado em busca tabu, para a resolução do problema. O grande diferencial dessa busca tabu é a região de busca (vizinhança) que é definida pela inclusão de restrições ao modelo, de forma a tornar a região de busca abrangente. O bom funcionamento do método depende, em alguns casos, da boa qualidade da solução inicial da busca tabu. Foram desenvolvidas estratégias de intensificação e diversificação levando em conta as novas estruturas da vizinhança. Em testes computacionais, a matheurística apresentou bons resultados, mostrando-se competitiva com métodos apresentados na literatura e mais abrangente quanto à quantidade de características que podem ser adicionadas ao problema sem a necessidade de alterar o método de solução.

A facilidade de adaptação do método e a boa qualidade das soluções obtidas nos levam a propor como trabalhos futuros: a) o desenvolvimento de matheurísticas baseadas na BTVA para outros problemas de dimensionamento de lotes; e b) a aplicação de heurísticas do tipo BTVA a problemas combinatórios, cuja relaxação linear se aproxime da envoltória convexa. 


\section{Referências Bibliográficas}

Aggarwal, A. \& Park, J. K., 1993. Improved algorithms for economic lot size problems. Operations Research, vol. 41, n. 3, pp. 549-571.

Armentano, V. A., França, P. M., \& Toledo, F. M. B., 1999. A network flow model for the capacitated lot-sizing problem. Omega, vol. 27, n. 2, pp. 275-284.

Bahl, H. C., Ritzman, L. P., \& Gupta, J. N. D., 1987. Determining lot sizes and resource requirements: A review. Operations Research, vol. 35, n. 3, pp. 329-345.

Barany, I., Van-Roy, T. J., \& Wolsey, L. A., 1984. Strong Formulations for Milti-item Capacitated Lot Sizing. Management Science, vol. 30, n. 10, pp. 1255-1261.

Belvaux, G. \& Wolsey, L. A., 1999. Lotsizelib: A library of models and matrices for lotsizing problems. Technical report, Universite Catholique de Louvain, Center for Operations Research and Econometrics.

Belvaux, G. \& Wolsey, L. A., 2000. bc-prod: A specialized branch-and-cut system for lotsizing problems. Management Science, vol. 46, n. 5, pp. 724-738.

Bennell, J. A. \& Dowsland, K. A., 2001. Hybridising tabu search with optimisation techniques for irregular stock cutting. Management Science, vol. 47, n. 8, pp. 1160-1172.

Beraldi, P., Ghiani, G., Grieco, A., \& Guerriero, E., 2008. Rolling-horizon and fix-andrelax heuristics for the parallel machine lot-sizing and scheduling problem with sequencedependent set-up costs. Computers $\&$ Operations Research, vol. 35, n. 11, pp. $3644-$ 3656 .

Bitran, G. R. \& Yanasse, H. H., 1982. Computational complexity of the capacitated lot size problem. Management Science, vol. 28, n. 10, pp. 1174-1186.

Blue, J. A. \& Bennett, K. P., 1998. Hybrid extreme point tabu search. European Journal of Operational Research, vol. 106, n. 3, pp. 676-688.

Brahimi, N., Dauzere-Peres, S., Najid, N., \& Nordli, A., 2006. Single item lot sizing problems. European Journal of Operational Research, vol. 168, n. 1, pp. 1-16.

Buschkühl, L., Sahling, F., Helber, S., \& Tempelmeier, H., 2008. Dynamic capacitated lotsizing problems: a classification and review of solution approaches. OR Spectrum, vol. 32, n. 2, pp. 231-261. 
Camargo, V. C. B., Mattiolli, L., \& Toledo, F. M. B., 2012. A knapsack problem as a tool to solve the production planning problem in small foundries. Computers $\& 5$ Operations Research, vol. 39, n. 1, pp. $86-92$.

Carreno, J. J., 1990. Economic lot scheduling for multiple products on parallel identical processors. Management Science, vol. 36, n. 3, pp. 348-358.

Caserta, M. \& Rico, E. Q., 2009. A cross entropy-lagrangean hybrid algorithm for the multiitem capacitated lot-sizing problem with setup times. Computers $\&$ Operations Research, vol. 36 , n. 2, pp. 530-548.

Caserta, M., Rico, E. Q., \& Uribe, A. M., 2008. A cross entropy algorithm for the knapsack problem with setups. Computers \& Operations Research, vol. 35, n. 1, pp. 241-252.

Denizel, M., Altekin, F. T., Süral, H., \& Stadtler, H., 2008. Equivalence of the LP relaxations of two strong formulations for the capacitated lot-sizing problem with setup times. $O R$ Spectrum, vol. 30, n. 4, pp. 773-785.

Denizel, M. \& Süral, H., 2006. On alternative mixed integer programming formulations and LP-based heuristics for lot-sizing with setup times. Journal of the Operational Research Society, vol. 57, n. 4, pp. 389-399.

Diaby, M., Bahl, H. C., Karwan, M. H., \& Zionts, S., 1992. Capacitated lot-sizing and scheduling by lagrangean relaxation. European Journal of Operational Research, vol. 59, n. 3 , pp. $444-458$.

Drexl, A. \& Kimms, A., 1997. Lot sizing and scheduling - survey and extensions. European Journal of Operational Research, vol. 99, n. 2, pp. 221-235.

Eppen, G. D. \& Martin, R. K., 1987. Solving multi-item capacitated lot-sizing problems using variable redefinition. Operations Research, vol. 35, n. 6, pp. 832-848.

Evans, J. R., 1985. Network-based optimization algorithms for the capacitated multi-item lot sizing problem. Computers $\&$ Industrial Engineering, vol. 9, n. 3, pp. 297-305.

Federgruen, A. \& Tzur, M., 1991. A simple forward algorithm to solve general dynamic lot sizing models with $\mathrm{n}$ periods in o(n $\log \mathrm{n})$ or o(n) time. Management Science, vol. $37, \mathrm{n}$. 8, pp. 909-925.

Ferreira, D., França, P. M., Kimms, A., Morabito, R., Rangel, S., \& Toledo, C. F. M., 2008. Heuristics and meta-heuristics for lot sizing and scheduling in the soft drinks industry: a comparison study. In Metaheuristics for Scheduling in Industrial and Manufacturing Applications, pp. 169-210.

Ferreira, D., Morabito, R., \& Rangel, S., 2010. Relax and fix heuristics to solve one-stage onemachine lot-scheduling models for small-scale soft drink plants. Computers $\&$ Operations Research, vol. 37, n. 4, pp. $684-691$. 
Fisher, M. L., Jaikumar, R., \& Wassenhove, V.-L. N., 1986. A multiplier adjustment method for the generalized assignment problem. Management Science, vol. 32, n. 9, pp. 1095-1103.

Flisberg, P., Lidén, B., \& Rönnqvist, M., 2009. A hybrid method based on linear programming and tabu search for routing of logging trucks. Computers $\&$ Operations Research, vol. 36, n. 4 , pp. $1122-1144$.

Florian, M. \& Klein, M., 1971. Deterministic production planning with concave costs and capacity constraints. Management Science, vol. 18, n. 1, pp. 12-20.

Florian, M., Lenstra, J. K., \& Rinnooy Kan, A. H. G., 1980. Deterministic production planning: Algorithms and complexity. Management Science, vol. 26, n. 7, pp. 669-679.

Glover, F., 1989. Tabu search-part i. ORSA Journal on Computing, vol. 1, n. 3, pp. 190-206.

Glover, F., 1990. Tabu search-part ii. ORSA Journal on Computing, vol. 2, n. 1, pp. 4-32.

Hindi, K. S., 1995. Computationally efficient solution of the multi-item, capacitated lot-sizing problem. Computers $\&$ Industrial Engineering, vol. 28, n. 4, pp. 709 - 719.

James, R. J. \& Almada-Lobo, B., 2011. Single and parallel machine capacitated lotsizing and scheduling: New iterative mip-based neighborhood search heuristics. Computers 86 Operations Research, vol. 38, n. 12, pp. $1816-1825$.

Jans, R. \& Degraeve, Z., 2007. Meta-heuristics for dynamic lot sizing: A review and comparison of solution approaches. European Journal of Operational Research, vol. 177, n. 3, pp. $1855-1875$.

Karimi, B., Fatemi Ghomi, S. M. T., \& Wilson, J. M., 2003. The capacitated lot sizing problem: a review of models and algorithms. Omega, vol. 31, n. 5, pp. 365-378.

Krarup, J. \& Bilde, O., 1977. Plant location, set covering and economic lot sizes: an o(mn) algorithm for structured problems. In Collatz, L. (ed.) Numerische Methoden bei Optimierungsaufgaben, Band 3, Optimierung bei Graphentheoretischen and Ganzzahligen Problemen, pp. $155-180$.

Lasdon, L. S. \& Terjung, R. C., 1971. An efficient algorithmfor multi-item scheduling. Operations Research, vol. 19, n. 4, pp. 946-969.

Love, S. F., 1973. Bounded production and inventory models with piecewise concave costs. Management Science, vol. 20, n. 3, pp. 313-318.

Lozano, S., Larraneta, J., \& Onieva, L., 1991. Primal-dual approach to the single level capacitated lot-sizing problem. European Journal of Operational Research, vol. 51, n. 3, pp. 354-366.

Maes, J., McClain, J. O., \& Van-Wassenhove", L. N., 1991. Multilevel capacitated lotsizing complexity and lp-based heuristics. European Journal of Operational Research, vol. 53, n. 2, pp. $131-148$. 
Maniezzo, V., Stützle, T., \& Vob, S., 2009. Matheuristics: Hybridizing Metaheuristics and Mathematical Programming. Annals of Information Systems. Springer.

Manne, A. S., 1958. Programming of economic lot sizes. Management Science, vol. 4, n. 23, pp. $115-135$.

Martello, S. \& Toth, P., 1977. Branch-and-bound algorithms for the solution of the general unidimensional knapsack problem. In M. Roubens(ed.) Advances in Operations Research, North-Holland, Amsterdan, pp. 295-301.

Martello, S. \& Toth, P., 1990. Knapsack Problems: Algorithms and Computer Implementations. John Wiley \& Sons, Chichester, NY.

Muller, L. F., Spoorendonk, S., \& Pisinger, D., 2012. A hybrid adaptive large neighborhood search heuristic for lot-sizing with setup times. European Journal of Operational Research, vol. 218 , n. 3 , pp. $614-623$.

Pedroso, J. P. \& Kubo, M., 2005. Hybrid tabu search for lot sizing problems. In Proceedings of the Second international conference on Hybrid Metaheuristics, pp. 66-77.

Pisinger, D., 2000. A minimal algorithm for the bounded knapsack problem. INFORMS Journal on Computing, vol. 12, n. 1, pp. 75-82.

Pochet, Y. \& Wolsey, L. A., 2006. Production Planning by Mixed Integer Programming. Springer.

Quadt, D. \& Kuhn, H., 2008. Capacitated lot-sizing with extensions: A review. 4OR - A Quarterly Journal of Operations Research, vol. 6, n. 1, pp. 61-83.

Sabbag, Z., 1993. Planejamento da produção em máquinas paralelas sob restrições de capacidade. Master's thesis, FEEC - UNICAMP.

Sahni, S. \& Gonzalez, T., 1976. P-complete approximation problems. Journal of the ACM, vol. 23 , n. 3 , pp. 555-565.

Selen, W. J. \& Heuts, R. M. J., 1990. Operational production planning in a chemical manufacturing environment. European Journal of Operational Research, vol. 45, n. 1, pp. 38 46.

Silva, C. \& Magalhaes, J. M., 2006. Heuristic lot size scheduling on unrelated parallel machines with applications in the textile industry. Computers $\&$ Industrial Engineering, vol. 50, n. $1-2$, pp. $76-89$.

Souza, K. X. X. \& Armentano, V. A., 1994. Multi-item capacitated lot-sizing by a cross decomposition based algorithm. Annals of Operations Research, vol. 50, n. 1, pp. 557-574.

Sung, C. S., 1986. A single-product parallel-facilities production-planning model. International Journal of Systems Science, vol. 17, n. 7, pp. 983-989. 
Süral, H., Denizel, M., \& Van-Wassenhove, L. N., 2009. Lagrangean relaxation based heuristics for lot sizing with setup times. European Journal of Operational Research, vol. 194, n. 1, pp. 51-63.

Toledo, F. M. B. \& Armentano, V. A., 2006. A lagrangian-based heuristic for the capacitated lot-sizing problem in parallel machines. European Journal of Operational Research, vol. 175, n. 2, pp. 1070-1083.

Toso, E. A. V., Morabito, R., \& Clark, A. R., 2009. Lot sizing and sequencing optimisation at an animal-feed plant. Computers $\mathcal{E}$ Industrial Engineering, vol. 57, n. 3, pp. $813-821$.

Trigeiro, W. W., 1987. The effect of setup time on production lot sizes. Production and Inventory Management, vol. 28, pp. 50-52.

Trigeiro, W. W., Thomas, L. J., \& McClain, J. O., 1989. Capacitated lot sizing with setup times. Management Science, vol. 35, n. 1, pp. 353-366.

Wagelmans, A. P. M., Van-Hoesel, S., \& Kolen, A., 1992. Economic lot-sizing: An o(n log n) algorithm that runs in linear time in the wagner-whitin case. Operations Research, vol. 40, n. 1, pp. S145-S156.

Wagner, H. M. \& Whitin, T. M., 1958. Dynamic version of the economic lot size model. Management Science, vol. 5, n. 1, pp. 89-96.

Wolsey, L. A., 1995. Progress with single-item lot-sizing. European Journal of Operational Research, vol. 86, n. 3, pp. 395-401.

Woodcock, A. J. \& Wilson, J. M., 2010. A hybrid tabu search/branch \& bound approach to solving the generalized assignment problem. European Journal of Operational Research, vol. 207 , n. 2 , pp. 566-578.

Wu, T. \& Shi, L., 2009. Hybrid nested partitions and relax-and-fix approach for capacitated multi-item lot sizing problem. In Proceedings of 2009 IEEE International Conference on Service Operation, Logistics and Informatics, pp. 359-364.

Zangwill, W. I., 1966. A deterministic multi-period production scheduling model with backlogging. Management Science, vol. 13, n. 1, pp. 105 - 119.

Zangwill, W. I., 1969. A backlogging model and a multi-echelon model of a dynamic economic lot size production system - a network approach. Management Science, vol. 15, n. 9, pp. $506-527$. 